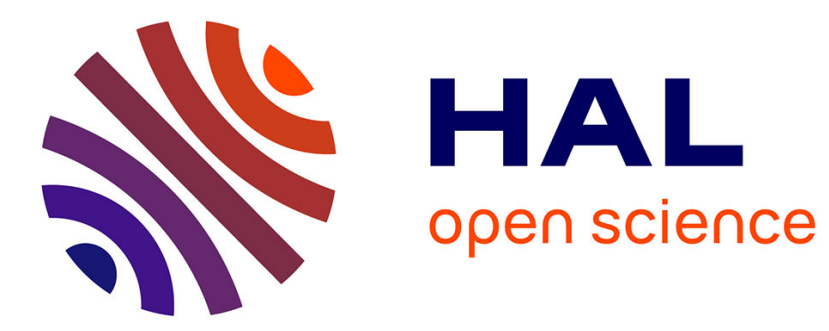

\title{
Lie of the Weak: Inconsistent Corporate Social Responsibility Activities of Chinese Zombie Firms
}

\author{
Shaozhen Han, Guoming Li, Michel Lubrano, Zhou Xun
}

\section{To cite this version:}

Shaozhen Han, Guoming Li, Michel Lubrano, Zhou Xun. Lie of the Weak: Inconsistent Corporate Social Responsibility Activities of Chinese Zombie Firms. 2020. halshs-02441264

\section{HAL Id: halshs-02441264 \\ https://shs.hal.science/halshs-02441264}

Preprint submitted on 15 Jan 2020

HAL is a multi-disciplinary open access archive for the deposit and dissemination of scientific research documents, whether they are published or not. The documents may come from teaching and research institutions in France or abroad, or from public or private research centers.
L'archive ouverte pluridisciplinaire HAL, est destinée au dépôt et à la diffusion de documents scientifiques de niveau recherche, publiés ou non, émanant des établissements d'enseignement et de recherche français ou étrangers, des laboratoires publics ou privés. 


\title{
amse
}

école d'économie d'aix-marseille aix-marseille school of economics

\section{Working Papers / Documents de travail}

\section{Lie of the Weak: Inconsistent Corporate Social Responsibility Activities of Chinese Zombie Firms}

\author{
Shaozhen Han \\ Guoming Li \\ Michel Lubrano \\ Zhou Xun
}




\title{
Lie of the Weak: \\ Inconsistent Corporate Social Responsibility Activities of Chinese Zombie Firms
}

\author{
Shaozhen Han', Guoming Li ${ }^{2,3}$, Michel Lubrano', 4 and Zhou Xun ${ }^{2 *}$
}

January 2020

\begin{abstract}
This study investigates the differences between zombie firms and non-zombie firms in corporate social responsibility activities such as reporting, disclosure and fulfillment. Using Chinese listing company data collected from 2009 to 2016, we apply a three stage model with a double Heckman correction to deal with potential self-selection/endogeneity bias and to measure the differences consistently. We found that zombie firms are less willing to release standalone corporate social responsibility reports than non-zombie firms. Among companies that release standalone corporate social responsibility reports, the corporate social responsibility disclosure of zombie firms is at least not worse than non-zombie firms, but the corporate social responsibility fulfillment is significantly lower. We conclude from this gap between disclosure and fulfillment to the hypocritical behavior of zombie firms, due to the absence of control in corporate social responsibility. We suggest that government should enhance supervision over zombie firms' corporate social responsibility activities and subsidies towards them in order to lower their economic damage. Supplementary analyses provide some clues concerning the heterogeneity of inconsistence in term of external support characteristics, ownership and censorship which require further studies.
\end{abstract}

Keywords: corporate social responsibility; zombie firms; reports; disclosure; fulfillment; hypocrisy

1 School of Economics and Management, Northwest University, Xi'an 710127, China; mailshaozhen@163.com

2 School of Economics, Jiangxi university of finance and economics, Nanchang 330013, China; liguomin@163.com (G.L.); decxun@hotmail.com (Z.X.)

3 Shuzun Information Technology (Shanghai) Ltd, Shanghai 200040, China;

4 CNRS, EHESS, Centrale Marseille, AMSE, Aix-Marseille University, Marseille 13001, France; michel.lubrano@univ-amu.fr

* Correspondence: decxun@hotmail.com 


\section{Introduction}

"Zombie firm" refers to companies that should go bankrupt because of low efficiency and unprofitability but still survive thanks to external support of government or bank sector (Kane, 1987). Zombie firms pose potentially very high threats to the economy as a whole, not only because of being inefficient and sluggish, but also due to the "spillover effect" as they distort market rules and undermine the competitiveness and innovation of the non-zombie firms (Caballero et al., 2008; Urionabarrenetxea et al., 2018). Despite their negative economic impact, the Chinese government, especially local governments, still help zombie firms because they "believe" that zombie firms take corporate social responsibilities (CSR), such as employment, social security, environmental protection, etc. (Banerjee and Hofmann, 2018; Caballero et al., 2008; Fukuda and Nakamura, 2011; Han et al., 2019; Kwon et al., 2015; Tan et al., 2016). The purpose of this paper is to answer the key question: do zombie firms really take adequate "social responsibilities" as expected?

Although a large number of studies have shown that participation in CSR activities can bring economic benefits to the firm, such returns are often of a long-term and uncertain nature (Nikolaeva and Bicho, 2011), and they might be perceived differently by zombie and non-zombie firms. Given the special characteristics of zombie firms and the Chinese economic/institution background, we are firstly interested in their CSR reports release behavior as compared to non-zombie firms. Moreover, CSR activities can be separated into CSR fulfillment (CSRF) and CSR disclosure (CSRD). Compared to CSRD activities, CSRF requires much more resources, so that image manipulation (CSRD) is much easier than actual fulfillment (Thorne et al., 2014). In the literature (Fassin and Buelens, 2011; Jahdi and Acikdilli, 2009), the gap between CSRD and CSRF is often qualified as hypocrisy. Because CSRD does not contain financial information and does actually lack strict supervision, zombie firms should have stronger incentive to play hypocrisy than other firms in order to keep their external support.

We notice that little attention has been devoted in the literature to the CSR hypocrisy of zombie firms. Therefore, it is important to distinguish zombie and non-zombie firms when studying CSR activities in order to understand differences in behavior and to supplement to the current hypocritical CSR literature. For finding empirical evidence, we use a large sample of 13,008 firm-years Chinese listed firms collected between 2009 and 2016. In this sample, we identify zombie firms following Caballero et al. (2008) and Fukuda and Nakamura (2011) and analyze how zombie statue affects the release of CSR reports. Among those who have released CSR reports, we use RKS (Rankings CSR ratings) rating issued by a Chinese rating agency to measure the CSRD level, as a proxy variable for CSRD. To measure the CSRF level, we use data in the "statement of cash flows" compiled by the "cash basis of accounting", which could hardly be manipulated. According to the stakeholder theory, we measure the CSRF score with cash paid for shareholders, creditors, employees, suppliers, and donations. Then, we examine whether zombie firms practice their words (identity between CSRD and CSRF) as well as non-zombie firms.

The econometric analysis of these data must consider the possibility of endogeneity bias (zombie status) and self-selection bias (observability of CSR activities). We propose to use a three stage model with a double Heckman correction with extension to panel data to analyze consistently the effect of zombie status on CSR activities

This study contributes to the literature in several ways. First, our study contributes to the fast-growing literature on the hypocrisy of CSR with a focus on Chinese institutional background. Second, our results add to the literature on zombie firms by providing the first evidence, to the best of our knowledge, on CSR activities of zombie firms. Beyond the existing literature on the negative consequences for economic growth (Caballero et al., 2008), we explore the negative impact of zombie firms on sustainable economic growth, such as lower CSR fulfillment and hypocritical CSR which might amplify their negative impacts in the long run. Third, we provide empirical insights for policy implications.

The remainder of the paper is organized as follows. Section 2 provides a review of the existing relevant literature. Section 3 presents the institutional background and hypothesis. Section 4 presents the research design. Empirical results are presented in Section 5 while Section 6 carries out further analysis. Section 7 discusses and concludes the paper. 


\section{Literature review}

\subsection{Motives, consequences and hypocrisy of CSR}

There are three main motivations for companies to engage in CSR activities (de Jong and van der Meer, 2017; Groza et al., 2011). The first is intrinsic motivation: driven by moral responsibility and altruism, an enterprise is willing to selflessly serve the public and take on more CSR activities (Graafland and Mazereeuw-Van der Duijn Schouten, 2012). The second is extrinsic motivation: the enterprise is self-centered with regards to CSR activities such as a self-service or strategic action, and expects to obtain economic or other benefits (Arena et al., 2018; Castro-González et al., 2019; He, Z. et al., 2018; John et al., 2019; Lau et al., 2018; Siueia et al., 2019; Xie et al., 2017). The third motivation concerns with stakeholder and legitimacy: to meet the expectations of both stakeholders and public to gain legitimacy (Momin and Parker, 2013). In practice, organizations often have a combination of motivations for CSR activities (de Jong and van der Meer, 2017). In addition to the above discussion, we shall also notice that CSR activities, especially the fulfillment actions usually imply intensive resource investment (Nikolaeva and Bicho, 2011). Under different institutional backgrounds, firms are facing heterogeneous legitimacy pressure. This leads to heterogeneous investment in CSR activities, which explains their diversification.

However, most of the literature assume that the CSRD is full information and can reflect the actual CSRF (Liao, L. et al., 2018) while the actual credibility and integrity of CSRD are relatively low (Lock and Seele, 2016; Luo et al., 2017; Michelon et al., 2015; Moneva et al., 2006; Ramus and Montiel, 2005; She and Michelon, 2019) ${ }^{1}$. When enterprises want to obtain economic benefits and legitimacy while being less willing to bear the cost of CSRF, they may have hypocritical CSR activities, which refers to doing is often contrary to saying (Fassin and Buelens, 2011). Hypocritical CSR refers to selective disclosure of positive information without full disclosure of negative information so as to create an overly positive corporate image (Bowen and Aragon-Correa, 2014). Green washing is a typical and common hypocritical CSR. In order to obtain consumers' recognition and purchase, the company advocates promoting green behavior on the one hand, but conceals activities that are not undertaken or even harm the environment on the other hand (Bowen and Aragon-Correa, 2014). Some companies pretend to be law-abiding, responsible and ethical in order to maintain good social credit, but indeed secretly evade taxes (Brunsson, 1989; Watson, 2015). Due to the lack of unified norm and practical regulatory system, hypocritical CSR is not easily perceived by government and public, and this can lead to adverse consequences. Hypocritical companies will be supported by the blinded government, and their products will be bought by confused consumers (Bhattacharya and Sen, 2004), and that directly harms the interests of consumers, government and the public. They also seriously affect the interests of other sincere socially responsible enterprises.

\subsection{The causes of zombie firms and their economic consequences}

The notion of "zombie firms" was first proposed by Kane (1987). It refers to insolvent, distressed enterprises that did not go bankrupt because of external support of banks or government. Zombie firm phenomena is ubiquitous all over the world, e.g. Japan (Caballero et al., 2008), UK (Papworth, 2013), South Korea (Hoshi and Kim, 2013) and the US (Hoshi and Kashyap, 2010). Zombie firms exist in major EU countries, with Portugal and Spain being the most seriously affected (Storz et al., 2017).

\footnotetext{
1 Ramus and Montiel (2005) found that the environmental statements between different organizations are similar, but the environmental implementation is quite different, which indicates that the environmental statement may be false or "green washing”. Moneva et al. (2006) found that the practice evidence seems to indicate that CSR is unreliable. Specifically, some organizations that claim to follow sustainability reports show irresponsibility in terms of sustainable behavior (such as gas emissions, social equity or human rights). She and Michelon (2019) found that companies have organized hypocrisy disclosures on social media (Facebook) to manage the perception of stakeholders and to maintain legitimacy. Luo et al. (2017) found that Chinese companies will carry out symbolic and low-quality CSR disclosure to deal with regulatory pressures. Michelon et al. (2015) found that CSR reporting practices are symbolic rather than substantive. Lock and Seele (2016) found that the credibility of the European CSR reports is not high, and there is still room for improvement.
} 
The bad motive for banks to cover up bad loans losses is considered as an important reason for the emergence of "zombie firms" (Hoshi and Kashyap, 2010). The second reason is the government's regulatory relaxation and support (Jaskowski, 2015). Under pressure to ensure employment, social stability, and economic growth, the government will relax regulations and connive the misconduct of banks. Some local governments intervene in bank credit decisions to help companies with financial crisis (He, Q. et al., 2018) and some local governments grant direct subsidy to help the zombie firms to survive (Huang and Zhang, 2018).

The literature also discusses the impact of zombie firms from two aspects: the enterprise itself and the spillover effects on other companies. First, the zombie firms themselves occupy a large amount of credit capital, equity capital, labor, and other resources while having lower operating efficiencies, which leads to higher total factor productivity loss (Banerjee and Hofmann, 2018). Second, zombie firms have spillover effects that affect non-zombie firms. Under the premise of limited total capital, zombie firms that occupy credit capital will lead to an increase in the financing costs and financing difficulty of non-zombie firms (Kwon et al., 2015), thus inhibiting the normal investments of non-zombie firms (Caballero et al., 2008). Zombie firms often use the malicious means of lowering product prices and increasing workers' wages, which seriously distort normal market competition (Papava, 2010). This will expose non-zombie firms to unfavorable competitive threats and hinder new potential market entrants (Urionabarrenetxea et al., 2018). In total, the external support under Chinese economic and institutional background may distort the behavior (especially, CSR activities in this paper) of zombie firms and hence amplify their negative impact on economic development.

\section{Institutional background and hypothesis}

\subsection{Institutional background of zombie firms and CSR practices in China}

\subsubsection{Institutional background of zombie firms in China}

Unsurprisingly, Chinese zombie firms receive greater governmental supports. Most Chinese banks are state owned, and the government often intervenes in bank credit decisions. For example, the interest-bearing liabilities of zombie firms have increased from around 70 billion yuan in 2009 to 400 billion yuan in 2016, which indicates a five times increase. In addition, the Chinese government often directly subsidizes zombie firms. According to the data disclosed by the listed company's annual reports, government subsidies received by zombie firms have increased from 1 billion yuan in 2009 to 10.5 billion yuan in 2015, and the accumulated amount until 2016 has exceeded 44.6 billion yuan. The dual support of government subsidies and bank credits has pushed the number and scale of Chinese zombie firms to an unpreceded high level, as shown in Fig. 1.

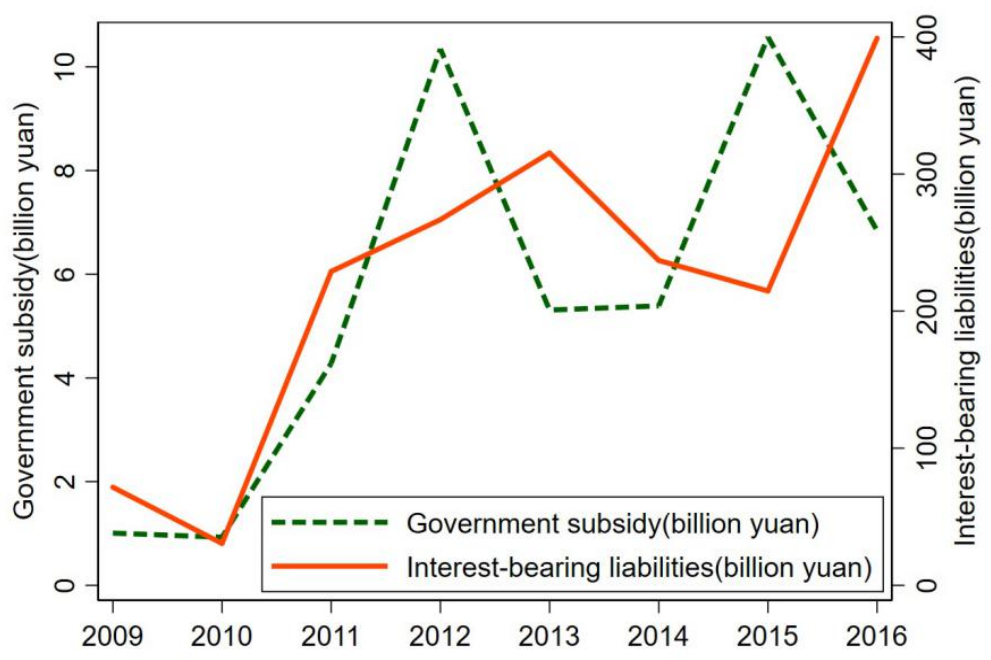


Fig. 1. Annual trend of external support for zombie firms (Source: Financial statements of Chinese listed companies, 2009-2016.)

\subsubsection{Institutional background of CSR practices in China}

There have been some seriously irresponsible incidents attributed to Chinese companies in recent years. The Chinese tainted milk powder incident in 2008 involved more than 10,000 infants and young children, seriously hurting the physical and psychological health of the victims. The 2017 vaccine event involved 650,000 unqualified vaccines produced by private producers and posed a serious safety hazard to vaccinators. In addition, some multinational corporations with good international reputation of being environmental responsible have repeatedly committed environmental violations in China, which shows a serious lack of CSR.

These serious irresponsible incidents have aroused wide public concern and inspired public expectations for enterprises to assume CSR. The Chinese government is also aware that such irresponsibility can constrain the sustainable development of the economy, and has begun to develop various policies to promote CSR practices². However, most of these policies encourage or require companies to voluntarily fulfill and disclose CSR. At the same time, more and more companies are launching standalone CSR reports ${ }^{3}$, which can help establishing effective interactions with stakeholders, demonstrating their good corporate image, and winning the trust of investors and consumers.

However, due to the absence of standard norms, there is a great subjectivity and arbitrariness in the content of CSR reports. Most of these reports have not been audited by a third party and lack corresponding oversight and credibility. To meet the expectations of the government and the public, some companies create responsible image by exaggerating or selectively disclosing their CSR. The CSRD of listed companies in China has always been low overall, and now there are new hypocrisy CSR behaviors which disclosure is greater than actual fulfillment. These problems are intertwined to make CSR practice more complicated. How to promote a more efficient CSR practice of Chinese enterprises has become an important practical question.

\subsection{Hypothesis development}

Legitimacy theory (LT), neo-institutional theory (NIT), and stakeholder theory (ST) are common simultaneous explanations for motivations and behaviors of CSR. These theories are complementary rather than competitive theories (Gray et al., 1995) so that we use the above three theories to analyze the CSR activities of zombie firms.

\subsubsection{The relation between zombie firms and the release of CSR reports}

The standalone CSR reports are a good way to communicate with the outside world (Wagner et al., 2009) because they contain the company's CSR activities in comprehensive detail (Thorne et al., 2014; Wagner et al., 2009). The release of CSR reports can not only meet the expectations of stakeholders and obtain legitimacy, but also create a good corporate image and access to the corresponding economic benefits. Therefore, if a company could bear the cost of CSR while facing

2 On 25 September, 2006, the Shenzhen Stock Exchange (SZSE) issued the "Guidelines for Social Responsibility of Listed Companies of Shenzhen Stock Exchange". On December 29, 2007, the State-owned Assets Supervision and Administration Commission (SASAC) issued the "Guiding Opinions on the Implementation of Social Responsibilities of Central Enterprises”. In April 2010, the “Guidelines for the Application of Internal Control of Enterprises” promulgated by the Ministry of Finance incorporated CSR into the entire internal control system. On May 14, 2008, the Shanghai Stock Exchange (SSE) issued two documents, "Notice on Strengthening the Social Responsibility of Listed Companies" and "Guidelines on Environmental Information Disclosure of Listed Companies on the Shanghai Stock Exchange". The China Securities Regulatory Commission (CSRC) issued the No. 37 announcement on December 31, 2010, requiring heavily polluting listed companies to disclose environmental responsibility in the "significant events" of the annual reports.

3 The SSE requires companies of listed in overseas and listed in the corporate governance sector to release CSR reports. The SZSE requires the companies belong of the "Shenzhen 100 Index" to release CSR reports. However, according to CSMAR and RKS, about $40 \%$ of these companies still do not release CSR reports. Moreover, we have not found that these companies are subject to appropriate penalties for not releasing. Therefore, this mandatory publication policy does not seem to be enforcement but voluntary. 
high level of stakeholders' CSR expectations and legitimacy pressure, it would be more willing to release the standalone CSR reports in order to enjoy the benefits. However, these driving factors are significantly lower in zombie than non-zombie firms, which makes zombie firms are less willing to release CSR reports than non-zombie firms.

First, the shortage of resources for zombie firms limits their ability to engage in CSR activities. The CSR activities require the company to bear the corresponding costs, which will consume a lot of resources and lead the short-term performance to decline (Nikolaeva and Bicho, 2011). Zombie firms often lose money year after year, and their profitability and operational efficiency are low, which leads to tight cash flow and shortage of resources (Caballero et al., 2008; Urionabarrenetxea et al., 2018). The primary object of zombie firm is to survive thus they are less likely to be able to afford the cost of carrying out CSR activities. Therefore, zombie firms are often CSR inactive.

Second, CSR is a long-term strategy that helps companies establishing sustainable competitive advantages, while with uncertainty (Adegbite et al., 2019; Liao, P.-C. et al., 2018; McWilliams et al., 2006; Nazeer, 2011; Porter and Kramer, 2006). The long-term strategy, such as CSR activities, is determined by the management team that includes the board of directors and senior executives (Davidson et al., 2018). Zombie firms are standing on the edge of bankruptcy. So that their management teams are more likely to be short sighted opportunists and rarely consider long-term benefits. Therefore, these management teams of zombie firms are often reluctant to assume CSR activities.

Third, the institutional environment of external support has changed the negotiation power of zombie firms and expectations of their stakeholders. These changes led to a lower legitimacy pressure for zombie firms. In order to help zombie firms to survive, local governments, as the most important stakeholders, must relax their CSR expectations, and give more support to zombie firms. In the case where the "helping hand" plays a crucial role (Shleifer and Vishny, 2002), the legitimacy pressure for the zombie firms will be much lower. As another important stakeholder, the public expectation concerning zombie firms' CSR might also decline. Large zombie firms have a large impact on local labor markets and on local economic system. Many small and medium-sized enterprises (SMEs) are attached to zombie firms for carrying out production and management activities. Once the zombie firms collapse, the employees of the zombie firms and the attached SMEs may lose their jobs. So they will also reduce their CSR expectations. For example, local residents continue to tolerate environmental hazards in heavily polluting zombie firms (Han et al., 2019). Therefore, according to the LT, NIT, and ST theories, the CSR activities of zombie firms are lower than non-zombie firms.

In addition, companies with lower CSR activities are reluctant to issue standalone CSR reports. This will expose the company's poor CSR activities to the outside world, and the company will be labeled as "irresponsible" by the public, and their reputation will be damaged, which will lead to a series of negative consequences. Therefore, irresponsible companies often do not disclose their CSR information (Belal and Cooper, 2011; Fassin and Buelens, 2011) or selectively remain silent (Carlos and Lewis, 2018), such as not issuing the standalone CSR reports.

Overall, the compromise of stakeholders under the special institutional environment reduces the zombie firms' legitimacy pressure; under the management of short-sighted and opportunistic, the resource-poor zombie firms have neither the ability nor the motivation to fulfill CSR; in order to avoid exposing of the irresponsible image, zombie firms to be silent or even less willing to release standalone CSR reports. Accordingly, we propose our first hypothesis as follows:

Hypothesis 1: Zombie status is negatively associated with the release of standalone CSR reports.

\subsubsection{The relation between zombie firms and CSRD and CSRF}

In recent years, the legitimacy pressure of Chinese enterprises engaged in CSR activities is increasing with institutional regulation reinforcements and public expectations changes overtime. On one hand, the public's demands on CSR have increased with the improvement of living standards. On the other hand, the central government pursuing sustainable development has also 
taken various measures to require enterprises to assume CSR. More and more Chinese companies are releasing standalone CSR reports ${ }^{4}$ to convey their CSR activities to external stakeholders.

Although the legitimacy pressure for zombie firms has been lower than for non-zombie firms, it has been increasing over time. First, the Chinese central government requires local governments to dispose of zombie firms and prohibits them to provide governmental support at will. Second, listed zombie firms need to publicly disclose information about external support received. The governmental support policy, such as local government subsidies and credit intervention, are the root cause of the survival of zombie firms, but the rationality of this policy is now being questioned by the central government and public investors. Zombie firms assume more CSR and deserve corresponding governmental support, which is the main basis for local governments and zombie firms to rationalize their external support policies. If the central government and the public investors believe that zombie firms are irresponsible, governmental support policy will suffer from widespread legitimacy suspicion and will be difficult to sustain. Therefore, when zombie firms' external support is subject to greater legitimacy pressure, they need to shape a responsible image in order to continue to obtain support and to survive.

However, the lack of resources inherent to zombie firms (Caballero et al., 2008; Urionabarrenetxea et al., 2018) has not changed fundamentally, which severely limits their CSR activities. So, the conflict between eager to shape a responsible external image and the inherent nature of low CSR activities may lead zombie firms adopting a hypocritical CSR tactic. Specifically, some zombie firms decided to disclose their CSR activities through exaggerated rhetoric in the CSR reports, and to shape themselves into a responsible image. This can meet the stakeholders' expectations to win their favor (Perez-Batres et al., 2012), to reduce the zombie firms' legitimacy pressure, and to obtain legitimacy in order to constantly receive government subsidies. In order to limit the CSRF cost, zombie firms have not actually fulfilled as much CSR as they promised (Fassin, 2005; Orlitzky et al., 2003).

The inconsistence between CSRD and CSRF is also the result of management opportunism. Without the support of the government, zombie firms will face bankruptcy and liquidation, and the zombie firms' senior management teams will face greater loss of benefits, such as job loss, income decline, etc. Hypocritical CSR allows companies to enjoy the CSR benefits without paying the cost of the corresponding CSRF. Once the opportunistic managements find that they can benefit from CSR image manipulation (Sikka, 2010), they will adopt this masking technique and embark on the path of hypocritical CSR (Riyanto and Toolsema, 2007).

Finally, the lack of supervision of CSRD provides an opportunity for exaggerated disclosures by zombie firms. First, laws and regulations on CSRD are imperfect and non-standard in China, which leads to greater freedom for companies to disclose CSR information (Martínez-Ferrero et al., 2017). Second, in China, many governments and institutions seem to have regulatory power over the company's CSR, such as the China Securities Regulatory Commission (CSRC), the Ministry of Finance, the State-owned Assets Supervision and Administration Commission (SASAC), the Ministry of the Environment, the Shanghai Stock Exchange (SSE) and the Shenzhen Stock Exchange (SZSE). However, these institutions do not undertake in fact major regulatory responsibilities. The decentralization of such regulatory powers and responsibilities has led to weak supervision of CSR. Third, unlike financial information, most of the CSRD (non-financial information) are not audited by independent third party. Fourth, the close ties between local governments and zombie firms have also reduced the regulatory pressures faced by zombie firms for false disclosures. Therefore, zombie firms can exaggerate CSRD while being unlikely to suffer from the risk of hypocritical disclosure, which further condone the hypocritical CSR of zombie firms. Consistent with these analyses, we postulate our second hypothesis:

4 According to CSMAR and RKS data, the CSR reports released by Chinese listed companies increased from 255 in 2009 to 558 in 2016, and increased by $118 \%$. 
Hypothesis 2: Among the firms who release CSR reports, zombie firms fulfill (CSRF) less their promises (CSRD) than non-zombie firms. That is, the CSRD and CSRF of zombie firms are inconsistent compared to non-zombie firms.

\section{Research design}

\subsection{Data and sample selection}

This study covers all Chinese firms that are listed on the Shanghai or Shenzhen stock exchanges, excluding financial institutions, from 2009 to 2016. We choose to start our sample from 2009 because the CSRD data of RKS begin to be published in 2009. CSR data are obtained from the CSR rating agency RKS. Other financial and governance data are obtained from the China Stock Market and Accounting Research (CSMAR) database, the WIND database, and the National Bureau of Statistics of China. After removing firms that have missing values, we obtain 13,008 firm-year observations (hereafter full sample), out of which 3,617 samples concerned CSR reports (hereafter subsample). Following prior literature, all independent and control variables (except ZOM) are lagged by one year (Luo et al., 2017). Next, we will discuss the main variables chosen for our analysis.

\subsection{Main variable definitions and descriptions}

\subsubsection{Measuring CSR activities}

From the perspective of CSR decision-making, we should consider three events. First, whether to release standalone CSR reports or not. Second, if reports are released, how detailed is the disclosed information, i.e. the level of CSRD. Third, to which extent the CSR has been fulfilled, i.e., the level of CSRF.

Throughout the paper, CSR_R is an indicator for the release of the standalone CSR reports which being 1 if a standard CSR report has been published, and 0 otherwise.

CSRD_S is an overall rating of CSRD activities, which is obtained from the third party RKS (Marquis and Qian, 2013). Just as KLD is widely used in United States research (Dhaliwal et al., 2011; Tran and O'Sullivan, 2018), RKS is widely used in CSRD research in China (Fassin, 2005; Luo et al., 2019; Wang et al., 2018; Yu and Zheng, 2018). RKS has set four zero-level indicators in terms of macrocosm, content, technique, and industry (MCTI) 5 . The rating ranges from 0 to 100 according to the content of the CSR reports. If a company does not release CSR reports, RKS will not evaluate it. Therefore, RKS's rating essentially reflects CSRD activities, rather than CSRF activities.

CSRF_S is an overall rating of CSRF activities. Chinese companies are mainly engaged in CSR activities under the guidance and encouragement of the government. The government emphasizes that the CSR is the responsibility of shareholders, creditors, employees, customers, consumers, suppliers, communities and other stakeholders, which is consistent with the ST theory (Lin et al., 2019; Margaretha Jastram and Klingenberg, 2018; Ranängen and Lindman, 2018). Therefore, we build a comprehensive CSRF indicator based on different stakeholders. In order to correctly reflect the CSRF level, according to the "cash basis of accounting", we use the data in the "statement of cash flows" to measure CSRF. Compared with the "balance sheet" and "income statement" prepared on "accrual basis of accounting", the "statement of cash flows" prepared on "cash basis of accounting" is less likely to be manipulated. At the request of the stakeholders of the Chinese regulatory authorities, and based on the data in the "statement of cash flows", we argue that the CSRF includes four aspects: "cash paid for dividends, profits or interest payments", "cash paid for employees", "cash paid for goods and services", and "cash paid for charitable purposes". We sum the above four

5 With further detailed division, RKS has set 15 first-level indicators and 63 second-level indicators. Specifically, 15 first-level indicators include strategy, governance, stakeholders, economic performance, labor and human rights, environment, fair operations, consumers, community participation and development, content balance, information comparable, report innovation, credibility and transparency, normative, accessibility, and information delivery effectiveness. 
cash outflows and then divide them by the operating income of the beginning year as a measure of CSRF activities.

\subsubsection{Identifying zombie firms}

To investigate CSR activities of zombie firms, it is critical to identify those firms that can be categorized as zombies. Depending on whether the company receives interest subsidies from the bank, Caballero et al. (2008), hereafter CHK, defined the zombies as those firms with actual interest payments below the assumed minimum risk-free interest payment. However, it is a noisy measurement method, in which the Type I error and Type II error are worth noting. Type I error is that zombies formed by obtaining evergreen loans rather than interest subsidies are mistakenly identified as non-zombies. Type II error is that non-zombies with low interest rates or interest-free loans due to good performance can be misidentified as zombies. In order to avoid these two types of errors, Fukuda and Nakamura (2011) modify the CHK measure using the "profit standard" and "evergreen loan standard" (FN-CHK). Due to the high accuracy of recognition, the FN-CHK model is widely used in the study of zombie firms (Han et al., 2019; Jiang et al., 2017; Shen and Chen, 2017; Tan et al., 2016). We use the FN-CHK model to identify zombie firms according to the following three steps.

Step1: Calculate the company's assumed minimum interest payment $R_{i t}^{*}$, which is the interest at the risk-free rate.

$$
R_{i t}^{*}=r s_{t-1} \times B S_{i, t-1}+\left(\frac{1}{5} \sum_{j=1}^{5} r l_{t-j}\right) \times B L_{i, t-1}+r c b_{\text {minl last } 5 \text { years }, t} \times \text { Bonds }_{i, t-1}
$$

where $B S_{i, t}$ are short-term bank loans with a term of less than one year, and $r S_{t}$ are the average interest rate of annual short-term loans. $B L i t$ are long-term bank loans with a term of more than one year (including long-term bank loans due within one year), and $r l_{t}$ are the average interest rate of annual long-term loans. Bondsit are a corporate bond issued (including convertible corporate bonds), and $r c b_{\text {min las } t} 5$ year, $t$ is the lowest interest rate on bonds and convertible corporate bonds that have been observed in the past five years.

Step2: Calculate interest subsidy quota and interest subsidy rate.

$$
G A P_{i t}=\frac{R_{i t}-R_{i t}^{*}}{B S_{i, t-1}+B L_{i, t-1}+B o n d s_{i, t-1}}
$$

where $R_{i, t}$ are company's actual interest payment amount, measured by the interest payment in the listed company's financial expense. The actual interest payment minus the assumed minimum interest payment $\left(R_{i t}-R^{*}{ }_{i t}\right)$, is the interest subsidy quota that the firms receives from the bank. (BSit $+B L_{i t}+B_{0}$ ndsit) are the total interest-bearing liabilities of listed companies. To eliminate the impact of debt amount, we divide the interest subsidy quota by the total interest-bearing liabilities at the beginning of the period. If $G A P_{i i}<0$, firm $i$ has received a subsidy, and its zombie index is 1 ; otherwise its zombie index is 0 .

Step3: Adjust the zombie index based on the "profitability criteria" and the "evergreen loan criteria". First, if the earnings before interest and tax (EBIT) of the zombie firms exceed the assumed minimum interest payment $\left(E B I T_{i t}>R^{*}{ }_{i t}\right)$, we reclassify the zombies as non-zombies based on "profitability criteria". Second, if a non-zombie's asset-liability ratio exceeded more than $50 \%$ in period $t-1$, and EBIT was lower than the assumed minimum interest payments in period $t$ $\left(E B I T_{i i}<R^{*}{ }_{i t}\right)$, and borrowing increased in period $t$, we reclassify such non-zombie as zombies according to the "evergreen loan criteria".

\subsection{Model specification and control variables}

\subsubsection{The basic model for the impact of zombie firms on the release of CSR reports}

To investigate the willingness to release CSR reports, we build the following binary response model: 


$$
C S R_{-} R_{i t}^{*}=\beta_{0}+Z O M_{i t} \lambda+X_{i, t-1}^{\prime} \alpha+\text { IndustryDums }+ \text { YearDums }+ \text { error }
$$

where CSR_R equals to 1 if $C S R_{-} R_{i t}^{*}>0$, and 0 otherwise. Variable ZOM equals to 1 when firm $i$ is recognized as a zombie firm at year $t$, and 0 otherwise, and the error term follows a standard normal distribution. According to Hypothesis 1, zombie firms are less likely to release CSR reports, thus we expect a negative sign for $\lambda$. To test Hypothesis 1 , we estimate Model (3) using the full sample.

Following previous literature (Ali et al., 2017; Banerjee et al., 2019; Chams and García-Blandón, 2019; García-Sánchez et al., 2019), we also include other control variables $X_{i, t-1}$ that might influence CSR activities. Specifically, we consider: INCOME it is the natural logarithm of a firm's total income at the end of the fiscal year; $R O A_{i t}$ is the profitability of firm $i$ calculated as net profit divided by total assets; $L E V_{i t}$ is the leverage ratio of firm $i$ calculated as total debt scaled by total assets in year $t ; A G E_{i t}$ is the natural logarithm of the listing age of firm $i$ in year $t ; T Q_{i t}$ is the Tobin's $Q$ of firm $i$ calculated as market value scaled by total assets in year $t ; C F O_{i t}$ is defined as cash flows divided by total assets; FIRST $_{i t}$ is the shareholding ratio of the largest shareholder; $B O A R D_{i t}$ is the natural logarithm of the total number of directors of firm $i$ in year $t$; MANSHRit is the ownership percentage by executive managers of firm $i$ in year $t$; DUALit is a dummy which equals to 1 for cases where the CEO and board Chair are the same person, or vice-CEO and Chair are the same, or CEO and vice-Chair are the same; $S T_{i t}$ is a dummy for trading status which equals 1 if firm $i$ is special treatment and 0 if normal trading; $C R O S S_{i t}$ is a dummy for cross-listing which equals 1 if firm $i$ is cross-listed overseas and 0 if listed only domestically; NATURE it is a dummy variable assigned value 1 for SOEs and 0 for non-SOEs in year $t$; IndustryDums is the industry specific dummy variables to take into account possible omitted industry characteristics; YearDums is the year specific dummy variables to control macroeconomic shocks and changes in regulations. To mitigate the impact of outliers, we winsorize all continuous financial variables at the $1 \%$ and $99 \%$ levels.

\subsubsection{The basic model for the impact of zombie firms on the CSRD and CSRF}

To test the effect of zombie firms on the CSRD and CSRF, we estimate the following model after controlling for other factors that have been documented to affect CSR activities:

$$
\begin{aligned}
& C S R D_{-} S_{i t}=\beta_{0}+Z_{Z O M} \lambda+X_{i, t-1}^{\prime} \alpha+\text { IndustryDums }+ \text { YearDums }+ \text { error } \\
& \text { CSRF_S } S_{i t}=\beta_{0}+Z_{Z O M} \lambda+X_{i, t-1}^{\prime} \alpha+\text { IndustryDums }+ \text { YearDums }+ \text { error }
\end{aligned}
$$

where CSRD_S $S_{i, t}$ represents variables describing the CSRD score of firm $i$ in year $t, C S R F \_S i, t$ represents variables describing the CSRF score of firm $i$ in year $t$. We include SIZE it which is the natural logarithm of a firm's total asset at the end of the fiscal year. Other variables are the same as Equation (3). According to Hypothesis 2, zombie firms are not worse than non-zombie firms in CSRD, but they are lower than non-zombie firms in CSRF, which reflects the contradiction between the disclosure and fulfillment of zombie firms' CSR activities. Therefore, we expect that ZOM has non-significant negative effect on the dependent variable CSRD_S in Model (4) and has significant negative impact on the dependent variable CSRF_S in Model (5). To test Hypothesis 2, we estimate the Models (4) and (5) using the subsample.

In Models (4) and (5), we also include control variables such as company characteristics, financial resources, governance characteristics, annual and industry effects. All continuous variables (except CSRD_S) are winsorized at the 1\% and 99\% levels.

\section{Empirical results}

In this section we present our empirical evidence. We start with descriptive statistics to illustrate some stylized facts. We then present preliminary results using naive models (simple Probit and linear regressions). To overcome potential self-selection and endogeneity bias, we propose a three stage model with a double Heckman correction using simulation methods. To identify the effect of potential endogenous variable, we apply and compare different identification strategies, i.e. 
using IV or parametric heteroscedasticity approaches. We then present the results accordingly and show that results obtained from proposed method lead to consistent findings. A set of robustness analysis is carried out to support our conclusions.

\subsection{Descriptive statistics}

Table 1 provides a description of the sample. Panel A presents the full sample distribution over time. First, we divide the sample into two groups: CSR reports released and non-CSR reports released. The CSR reports released by Chinese listed companies increased from 255 in 2009 to 558 in 2016, and 3,724 CSR reports were released. Second, we divide the full sample into two groups: zombie firms and non-zombie firms. The number of zombie firms has increased from 90 in 2009 to 263 in 2015, indicating that the situation of zombie firms in Chinese listed companies is even more serious. The proportion of zombie firms in the sample is about $9.92 \%$.

Panel B shows the distribution of the subsample over time. We also divided the subsample into two groups of zombies and non-zombies. The proportion of zombie firms in the subsample which released CSR reports dropped to around $7.85 \%$, which initially indicates that the zombie firms have a lower willingness to release CSR reports. However, there are still 284 zombie firms that have released CSR reports. What kind of pressure and motivation have led these zombie firms to release CSR reports? How do these zombie firms' CSRD and CSRF differ from those of non-zombie firms?

Table 1

Sample description

Panel A: The full sample used for Model (3)

\begin{tabular}{|c|c|c|c|c|c|c|c|c|c|}
\hline year & \multicolumn{2}{|c|}{ Non-CSR reports release } & \multicolumn{2}{|c|}{ CSR reports release } & \multicolumn{2}{|c|}{ Non-zombie firms } & \multicolumn{2}{|c|}{ Zombie firms } & Total \\
\hline 2009 & 558 & $68.63 \%$ & 255 & $31.37 \%$ & 723 & $88.93 \%$ & 90 & $11.07 \%$ & 813 \\
\hline 2010 & 990 & $71.84 \%$ & 388 & $28.16 \%$ & 1283 & $93.11 \%$ & 95 & $6.89 \%$ & 1378 \\
\hline 2011 & 1126 & $73.16 \%$ & 413 & $26.84 \%$ & 1401 & $91.03 \%$ & 138 & $8.97 \%$ & 1539 \\
\hline 2012 & 1276 & $73.04 \%$ & 471 & $26.96 \%$ & 1545 & $88.44 \%$ & 202 & $11.56 \%$ & 1747 \\
\hline 2013 & 1348 & $72.01 \%$ & 524 & $27.99 \%$ & 1689 & $90.22 \%$ & 183 & $9.78 \%$ & 1872 \\
\hline 2014 & 1360 & $70.91 \%$ & 558 & $29.09 \%$ & 1729 & $90.05 \%$ & 189 & $9.84 \%$ & 1918 \\
\hline 2015 & 1342 & $70.67 \%$ & 557 & $29.33 \%$ & 1636 & $82.63 \%$ & 263 & $13.28 \%$ & 1899 \\
\hline 2016 & 1284 & $69.71 \%$ & 558 & $30.29 \%$ & 1682 & $82.01 \%$ & 160 & $7.80 \%$ & 1842 \\
\hline Total & 9284 & $71.37 \%$ & 3724 & $28.63 \%$ & 11688 & $87.88 \%$ & 1320 & $9.92 \%$ & 13008 \\
\hline
\end{tabular}

Panel B: The subsample used for Models (4) and (5)

\begin{tabular}{cccccc}
\hline \multirow{2}{*}{ year } & \multicolumn{2}{c}{ Non-zombie firms } & \multicolumn{2}{c}{ Zombie firms } & \multirow{2}{*}{ Total } \\
\hline 2009 & 166 & percent & number & percent & $4.05 \%$ \\
2010 & 373 & $95.95 \%$ & 13 & $3.37 \%$ & 386 \\
2011 & 388 & $94.63 \%$ & 21 & $5.13 \%$ & 409 \\
2012 & 417 & $88.91 \%$ & 52 & $11.09 \%$ & 469 \\
2013 & 484 & $92.72 \%$ & 38 & $7.28 \%$ & 522 \\
2014 & 514 & $92.45 \%$ & 42 & $7.55 \%$ & 556 \\
2015 & 479 & $87.25 \%$ & 70 & $12.75 \%$ & 549 \\
2016 & 512 & $92.59 \%$ & 41 & $7.41 \%$ & 553 \\
Total & 3333 & $92.15 \%$ & 284 & $7.85 \%$ & 3617 \\
\hline
\end{tabular}

Table 2 provides summary statistics for the main variables of our study. Panel A shows the descriptive statistics for the full sample in Model (3). The dependent binary variable CSR_R has mean 0.286 indicating $28.6 \%$ of observations in our sample disclosed CSR reports. This is basically consistent with other Chinese CSRD studies (Yu and Zheng, 2018), indicating that Chinese companies' CSR reports are still at a low level (Liao et al., 2017). This ratio is also much lower than the $41.4 \%$ observed in some US studies (Holder-Webb et al., 2009). The dependent binary variable ZOM has mean 0.101 indicating $10.1 \%$ of observations in our sample are identified as zombie firms. This proportion is consistent with the results using FN-CHK model in other studies (Shen and Chen, 
2017). This is however lower than the results of about $20 \%$ of those who simply use the CHK model (Jiang et al., 2017).

Panel B shows the descriptive statistics for the subsample used in Models (4) and (5). The average CSRD_S rating is 37.772 , with a range of 11.690 to 87.948 . The average CSRF_S rating is 1.010, with a range of 0.297 to 4.699. The standard deviations of CSRD_S and CSRF_S are 12.354 and 0.458 , respectively. The coefficient of variation for CSRD_S and CSRF_S are 0.327 and 0.454 , respectively. The coefficient of variation of CSRF_S is $38.84 \%$ greater than CSRD_S ((0.454-0.327)/0.327), which indicates that the CSRF difference is higher than the CSRD difference, and it seems to show the inconsistency between CSRD and CSRF. The effects of zombie firms on these variations will be studied in detail later. The mean value of $Z O M$ is 0.079 , which indicates that $7.9 \%$ of the subsample were zombie firms. This is lower than the proportion of zombie firms in the full sample. This seems to indicate that zombie firms are less willing to release standalone CSR reports, which is basically consistent with our Hypothesis 1 . The mean value of NATURE is 0.666 indicating that $66.6 \%$ of the subsample were SOEs. This is higher than the proportion of SOEs in the full sample $(0.666>0.488)$. This seems to indicate that SOEs are more willing to release CSR reports.

\section{Table 2}

Summary statistics

Panel A. Summary Statistics for Model (3)

\begin{tabular}{lccccccc}
\hline VarName & Obs & Mean & SD & CV & Min & Median & Max \\
\hline CSR_R & 13008 & 0.286 & 0.452 & 1.579 & 0.000 & 0.000 & 1.000 \\
ZOM & 13008 & 0.101 & 0.302 & 2.976 & 0.000 & 0.000 & 1.000 \\
NATURE & 13008 & 0.488 & 0.500 & 1.025 & 0.000 & 0.000 & 1.000 \\
\hline \multicolumn{7}{l}{ Panel B. Summary Statistics } & \multicolumn{7}{c}{ Models (4) and (5) } \\
\hline CSRD S & 3617 & 37.772 & 12.354 & 0.327 & 11.690 & 35.030 & 87.948 \\
CSRF_S & 3617 & 1.010 & 0.458 & 0.454 & 0.297 & 0.948 & 4.699 \\
ZOM & 3617 & 0.079 & 0.269 & 3.426 & 0.000 & 0.000 & 1.000 \\
NATURE & 3617 & 0.666 & 0.472 & 0.708 & 0.000 & 1.000 & 1.000 \\
\hline
\end{tabular}

\subsection{Univariate tests}

In Table 3 we report the univariate mean-difference $t$-statistics of main variables between zombie and non-zombie firms. Panel A shows the mean-differences between zombie and non-zombie firms for the full sample. The $C S R \_R$ ratio for zombie and non-zombie firms are $22.0 \%$ and $29.4 \%$ respectively where the difference is $7.4 \%$ and significant ( $p$ value $<0.01$ ). This initially shows that zombie firms have taken a lower CSR reports release ratio and presumably supports our Hypothesis 1 that zombie firms are less likely to release CSR reports.

Panel B refers to the mean-differences between zombie and non-zombie firms for the subsample. We found no significant difference for CSRD_S between the two groups, and secondly, while $C S R F \_S$ in zombie group has mean value at 0.945 which is significantly lower ( $p$ value $<0.05$ ) than the mean value of the non-zombie group (1.015). This preliminary shows that zombie firms have roughly the same level of CSRD as non-zombie firms, and that zombie firms have lower levels of CSRF than non-zombie firms. So, it provides initial support for Hypothesis 2.

\section{Table 3}

Univariate tests

Panel A. univariate tests of Model (3)

\begin{tabular}{|c|c|c|c|c|c|c|}
\hline & \multicolumn{2}{|c|}{$Z O M=0$} & \multicolumn{2}{|c|}{$Z O M=1$} & \multirow{2}{*}{$\frac{\text { mean-diff }}{0.074^{* * *}}$} & \multirow{2}{*}{$\begin{array}{r}\text { t-Test } \\
5.653\end{array}$} \\
\hline CSR $R$ & 11688 & 0.294 & 1320 & 0.220 & & \\
\hline NATURE & 11688 & 0.478 & 1320 & 0.577 & $-0.099^{* * *}$ & -6.816 \\
\hline \multicolumn{7}{|c|}{ Panel B. univariate tests of Models (4) and (5) } \\
\hline CSRD_S & 3333 & 37.751 & 284 & 38.027 & -0.277 & -0.362 \\
\hline CSRF_S & 3333 & 1.015 & 284 & 0.945 & $0.070^{* *}$ & 2.474 \\
\hline NATURE & 3333 & 0.656 & 284 & 0.789 & $-0.133^{* * *}$ & -4.580 \\
\hline
\end{tabular}




\section{Notes: ${ }^{*}{ }^{* *}$ or ${ }^{* * *}$ indicates a significance level at $10 \%, 5 \%$, and $1 \%$ respectively.}

\subsection{Zombie firms and the release of CSR reports}

We test Hypothesis 1 by identifying the association between zombie firms and the release of CSR reports, as proposed in Model (3). Column (1) in Table 4 are the regression results of the Probit models. We found significant negative effect of being ZOM on CSR_R. Again, our first regression provides evidence that zombie firms are less likely to release CSR reports than non-zombie firms. The regression results for other control variables are basically consistent with the existing literature (Dhaliwal et al., 2011; Han et al., 2019; Marquis and Qian, 2013).

\section{Table 4}

Zombie firms and the CSR activities

\begin{tabular}{|c|c|c|c|}
\hline & (1) Probit & (2) OLS & (3) OLS \\
\hline & CSR_R & CSRD_S & CSRF_S \\
\hline \multirow[t]{2}{*}{ ZOM } & $-0.236^{* * *}$ & -0.661 & $-0.105^{* * *}$ \\
\hline & $(0.083)$ & $(0.628)$ & $(0.025)$ \\
\hline \multirow[t]{2}{*}{ INCOME } & $0.770^{* * *}$ & & \\
\hline & $(0.025)$ & & \\
\hline \multirow[t]{2}{*}{ SIZE } & & $3.544^{* * *}$ & $0.032^{* * *}$ \\
\hline & & $(0.206)$ & $(0.008)$ \\
\hline \multirow[t]{2}{*}{$R O A$} & $1.452^{* *}$ & -3.794 & $-0.426^{* *}$ \\
\hline & $(0.613)$ & $(4.298)$ & $(0.216)$ \\
\hline \multirow[t]{2}{*}{$L E V$} & $-1.460^{* * * *}$ & $-2.962^{* *}$ & $0.186^{* * *}$ \\
\hline & $(0.166)$ & (1.259) & $(0.062)$ \\
\hline \multirow[t]{2}{*}{$A G E$} & $0.228^{* * *}$ & $-2.310^{* * *}$ & 0.018 \\
\hline & $(0.044)$ & $(0.413)$ & $(0.014)$ \\
\hline \multirow[t]{2}{*}{$T Q$} & $0.041^{* *}$ & $0.264^{*}$ & $0.026^{* * *}$ \\
\hline & $(0.020)$ & $(0.144)$ & $(0.007)$ \\
\hline \multirow[t]{2}{*}{ CFO } & -0.161 & $9.533^{* * *}$ & $-1.311^{* * *}$ \\
\hline & $(0.332)$ & $(2.540)$ & $(0.143)$ \\
\hline \multirow[t]{2}{*}{ FIRST } & -0.002 & $0.026^{* *}$ & 0.000 \\
\hline & $(0.002)$ & $(0.012)$ & $(0.001)$ \\
\hline \multirow[t]{2}{*}{$B O A R D$} & $0.395^{* * *}$ & $3.824^{* * *}$ & -0.025 \\
\hline & $(0.134)$ & $(1.052)$ & $(0.042)$ \\
\hline \multirow[t]{2}{*}{ MANSHR } & $-0.548^{* * *}$ & $2.578^{*}$ & 0.069 \\
\hline & $(0.193)$ & $(1.522)$ & $(0.060)$ \\
\hline \multirow[t]{2}{*}{ DUAL } & -0.091 & $-1.143^{* * *}$ & -0.002 \\
\hline & $(0.061)$ & $(0.441)$ & $(0.022)$ \\
\hline \multirow[t]{2}{*}{$S T$} & $-0.310^{*}$ & 0.173 & -0.088 \\
\hline & $(0.187)$ & $(1.580)$ & $(0.110)$ \\
\hline \multirow[t]{2}{*}{ CROSS } & $0.253^{* * *}$ & $4.390^{* * *}$ & $0.049^{* *}$ \\
\hline & $(0.084)$ & $(0.684)$ & $(0.023)$ \\
\hline \multirow[t]{2}{*}{ NATURE } & $0.286^{* * *}$ & $0.802^{*}$ & $-0.057^{* * *}$ \\
\hline & $(0.056)$ & $(0.440)$ & $(0.021)$ \\
\hline \multirow[t]{2}{*}{ Constant } & $-17.629^{* * *}$ & $-56.626^{* * *}$ & 0.320 \\
\hline & $(0.577)$ & $(4.730)$ & $(0.195)$ \\
\hline Year effects & Yes & Yes & Yes \\
\hline Industry effects & Yes & Yes & Yes \\
\hline Observations & 13008 & 3617 & 3617 \\
\hline Pseudo/Adjusted $R^{2}$ & 0.193 & 0.336 & 0.179 \\
\hline
\end{tabular}




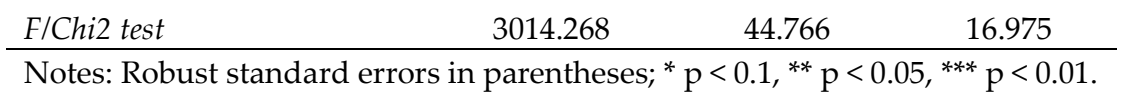

\subsection{Zombie firms and CSRD and CSRF}

In Columns (2) and (3) of Table 4 we report estimates for Models (4) and (5) with dependent variable CSRD_S and CSRF_S respectively using the subsample who released CSR reports. The VIFs of the key variables ranged from 1.01 to 2.51 , which indicates that the results are not subject to severe collinear interference.

The coefficient of ZOM to CSRD_S in Column (2) of Table 4 is not significant, which shows that CSRD are not significantly different between zombies and non-zombies, that is, zombies are just as "good" as non-zombies say they are. The coefficient of ZOM for CSRF_S in Column (3) of Table 4 is significantly negative, which indicates that the CSRF of zombie firms is significantly lower than non-zombie firms, that is, zombie firms do worse than non-zombie firms on average. Thus, after controlling for a series of exogenous variables, we reach the same conclusion as previous preliminary findings that there is no significant difference between zombie and non-zombie group in term of CSRD_S ("words") but the former group behave significantly lower level for CSRF_S ("actions"). This indicates the zombie firms did less than what they described.

\subsection{Endogeneity issue}

Our previous results obtained from naive models might be biased because of endogeneity risks. For instance, zombie status could be simultaneously endogenous to all CSR activities, including CSR reports release, CSRD and CSRF while the latter two activities are observed conditional on the release of CSR reports. To obtain the consistent results and to benefit from the rich information contained in the panel structure, we consider a three stage model with a double Heckman correction implemented as follows: (i) We estimate a triangular bivariate panel Probit model (see Model 6 below) with individual random effects to measure the effect of being zombie (stage one and two, see Model 6 below which corresponds to Hypothesis 1); (ii) In a third stage, we introduce the two previously calculated correction terms (Inverse Mills ratio, hereafter IMR) as regressors in Model $(4) /(5)$ respectively (Hypothesis 2). Moreover, to overcome the fragility of using conventional instrument variables, we consider a pure statistical approach (using heteroscedasticities) and a relevant discussion follows.

5.5.1. A three stage model with Heckman corrections: stage 1 and 2, zombie status and CSR reports release

In our naive estimation, we found empirical evidence to support Hypothesis 1 and 2. However, the effect of zombie status may be endogenous to the CSR reports releasing behavior, meanwhile both variables are binary. In order to obtain an unbiased estimate of zombie status upon CSR_R response, we consider a triangular bivariate Probit model with individual random effects:

$$
\left\{\begin{array}{l}
Z O M_{i t}^{*}=X_{i t}^{\prime} \alpha+Z_{i t}^{\prime} \gamma+\pi_{i}+v_{i t} \\
C S R_{-} R_{i t}^{*}=X_{i t}^{\prime} \beta+Z O M_{i t} \lambda+\tau_{i}+\varepsilon_{i t}
\end{array}\right.
$$

where $Z_{i t}$ is a set of instrumental variables which are excluded from structural equations. Specifically, we use employee density (PEMPLOYEE) as an instrument, despite criticisms. PEMPLOYEE is calculated as total number of employees divided by total assets. The major motivation (excuse) of the Chinese government to help zombie firms is to maintain employment and social stability (Shen and Chen, 2017). As a result, the bankruptcy of labor-intensive companies has greater impact on local government goals. All other things being equal, the government is more willing to help companies with more employees to avoid bankruptcy, which leads to these companies to become zombies. As a result, companies with more employees are more likely to get governmental support, and more likely to become zombie firms. CSR activities are major decisions made by a small number of core figures, such as the board of directors and senior executives 
(Davidson et al., 2018), after careful consideration of the power of stakeholders. Most grassroots employees are unable to participate in or to influence the CSR decisions. The symbolic trade unions of Chinese companies are relatively small and are at pain to influence the management team's decision-making (Zhu et al., 2011). Therefore, the increase of PEMPLOYEE does not affect the company's CSR decision-making (CSR reports release, CSRD and CSRF), but it influences the formation of zombie firms.

$\pi_{i}: N\left(0, \sigma_{z d}^{2}\right)$ and $\tau_{i}: N\left(0, \sigma_{c d}^{2}\right)$ are the individual random effects. For identification reasons, we have to impose that $\sigma_{z d}^{2}+\sigma_{v}^{2}=1$ and $\sigma_{c d}^{2}+\sigma_{\varepsilon}^{2}=1$ (Cappellari and Jenkins, 2004). We assume that the two individual random effects are correlated with covariance equal to $\rho \sigma_{v} \sigma_{\varepsilon}$ and $-1<\rho<1$. Because we must consider $T$ waves of observations and in each wave there're two equations to be evaluated, the full variance-covariance matrix $\Sigma$ is a $2 T \times 2 T$ matrix as follows:

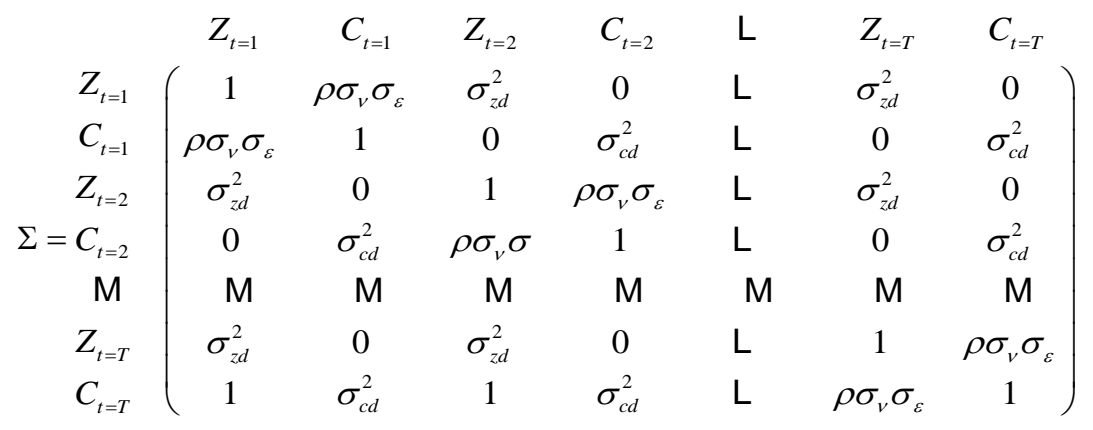

As this matrix is positive definite, it can be Cholesky decomposed and thus be delivered to the conventional GHK simulator for conducting simulation maximum likelihood inference. The endogeneity problem is present whenever $\rho \sigma_{v} \sigma_{\varepsilon}$ is non-zero.

The probability of the joint success events at period 1 is given by:

$$
\begin{aligned}
\operatorname{Pr}\left(Z_{i, t=1}\right. & \left.=1, C S R_{-} R_{i, t=1}=1\right) \\
& =\operatorname{Pr}\left(v_{i 1}+\pi_{i}<X_{i 1}^{\prime} \alpha+Z_{i 1}^{\prime} \gamma, \varepsilon_{i 1}+\tau_{i}<X_{i 1}^{\prime} \beta+Z O M_{i 1} \lambda\right) \\
& =\operatorname{Pr}\left(v_{i 1}+\pi_{i}<X_{i 1}^{\prime} \alpha+Z_{i 1}^{\prime} \gamma\right) \times \operatorname{Pr}\left(\varepsilon_{i 1}+\tau_{i}<X_{i 1}^{\prime} \beta+Z O M_{i 1} \lambda \mid v_{i 1}+\pi_{i}<X_{i 1}^{\prime} \alpha+Z_{i 1}^{\prime} \gamma\right)
\end{aligned}
$$

To implement, we apply the GHK simulation. Let $A$ be the lower triangular Cholesky decomposition of the variance-covariance $\Sigma$ such that $A A^{\prime}=\Sigma$ with:

$$
A=\left(\begin{array}{cccc}
a_{11} & 0 & \ldots & 0 \\
a_{21} & a_{22} & \cdots & 0 \\
\mathrm{M} & \mathrm{M} & a_{i i} & 0 \\
a_{2 T, 1} & a_{2 T, 2} & \mathrm{~L} & a_{2 T, 2 T}
\end{array}\right)
$$

We consider $2 T$ iid standard normal random variables $\eta_{m}, m=1,2, \ldots, 2 T$, so that we can express the error terms as a linear combination of the two independent $\eta_{m}$, an expanded notation being:

$$
\begin{aligned}
& v_{i 1}+\pi_{i}=a_{11} \eta_{1} \\
& \varepsilon_{i 1}+\tau_{i}=a_{11} \eta_{1}+a_{22} \eta_{2} \\
& \quad \mathrm{~L} \\
& v_{i T}+\pi_{i}=a_{2 T-1,1} \eta_{1}+\mathrm{L}+a_{2 T-1,2 T-1} \eta_{2 T-1} \\
& \varepsilon_{i 1}+\tau_{i}=a_{2 T, 1} \eta_{1}+\mathrm{L}+a_{2 T, 2 T} \eta_{2 T}
\end{aligned}
$$

Therefore, we can rewrite joint probability of the first two success events as:

$$
\begin{aligned}
\operatorname{Pr}\left(Z O M_{i t=1}\right. & \left.=1, C S R_{-} R_{i t=1}=1\right) \\
& =\operatorname{Pr}\left(\eta_{1}<\frac{X_{i 1}^{\prime} \alpha+Z_{i 1}^{\prime} \gamma}{a_{11}}\right) \times \operatorname{Pr}\left(\eta_{2}<\frac{X_{i 1}^{\prime} \beta+Z O M_{i 1} \lambda-a_{21} \eta_{1}^{*}}{a_{22}}\right)
\end{aligned}
$$


where $\eta_{1}^{*}$ is the truncated standard normal variate with upper truncation point at $\frac{X_{i 1}^{\prime} \alpha+Z_{i}^{\prime} \gamma}{a_{11}}$. If we have $R$ draws of $\eta_{1}^{*}$, the measure of the conditional probability is straightforward, the simulated joint probability can be approximated by the arithmetic mean of each probability given the $r^{\text {th }}$ random draw of $\eta_{1}^{r}$ :

$$
\overline{\mathrm{Pr}_{i}}\left(Z O M_{t=1}, C S R_{-} R_{t=1}\right)_{G H K}=\frac{1}{R} \sum_{r=1}^{R}\left[\operatorname{Pr}_{Z_{O M}} \times \operatorname{Pr}_{C S R_{-} R_{t=1}}^{r}\right]
$$

Similarly, we obtain the simulated probabilities for each $t$ and then we have the likelihood function for individual $i$ as:

$$
L_{G H K, i}=\frac{1}{R} \sum_{r=1}^{R}\left[\operatorname{Pr}_{\mathrm{ZOM}_{i, t=1}} \times \operatorname{Pr}_{C S R_{-} R_{i, t-1}}^{r} \times \prod_{i, t=2}^{T}\left(\operatorname{Pr}_{\mathrm{ZOM}_{i t}}^{r} \times \operatorname{Pr}_{C S R_{-} R_{i t}}^{r}\right)\right]
$$

In Table 5, we report the empirical results using the proposed bivariate Probit model with individual random effects. When comparing it to Table 4, we obtain similar estimates, except that the coefficient of zombie status now has a higher magnitude, although the sign and significance level remain unchanged. On the other hand, both individual random effects are significant and the correlation between the two Probit processes is significantly positive. Although these results lead to the conclusion that the naive model lead to biased estimate of zombie effect, the empirical results shown here still support Hypothesis 1.

Table 5

\begin{tabular}{|c|c|c|c|}
\hline \multicolumn{2}{|c|}{$\begin{array}{c}\text { 1) } \\
\text { ZOM }\end{array}$} & \multicolumn{2}{|c|}{$\begin{array}{c}(2) \\
C S R \_R\end{array}$} \\
\hline PEMPLOYEE & $\begin{array}{l}-0.055^{* * *} \\
(0.015)\end{array}$ & $Z O M$ & $\begin{array}{c}-1.074^{* * *} \\
(0.044)\end{array}$ \\
\hline Other controls & Yes & & Yes \\
\hline Year effects & Yes & & Yes \\
\hline Industry effects & Yes & & Yes \\
\hline$\rho \sigma_{v} \sigma_{\mathcal{E}}$ & $\begin{array}{l}0.590^{\text {*** }} \\
(0.090)\end{array}$ & & \\
\hline$\sigma_{z d}$ & $\begin{array}{l}0.353^{* * *} \\
(0.020)\end{array}$ & $\sigma_{c d}$ & $\begin{array}{l}0.764^{* * *} \\
(0.025)\end{array}$ \\
\hline
\end{tabular}

The first two stages: A bivariate Probit model

Likelihood -6647.966

Notes: Robust standard errors in parentheses; ${ }^{*} \mathrm{p}<0.1,{ }^{* *} \mathrm{p}<0.05,{ }^{* * *} \mathrm{p}<0.01$.

\subsubsection{A three stage model with Heckman corrections: stage 3, zombie status and CSRD/CSRF}

We now analyze how zombie status affects CSRD and CSRF. As zombie status might be endogenous and as the observability of CSR might cause selection bias, we use the IMR calculated from the previous bivariate Probit estimate to implement the third stage with Heckman corrections. As we assume that the third stage (CSRD_S/CSRF_S) equations' idiosyncratic errors are respectively correlated with the error part of the previous two events' equations ${ }^{6}$.

6 In our three stage model with a double Heckman correction, the first stage refers to upper Equation of Model (6), the second stage refers to lower Equation of Model (6) and the third stage refers to Equation (4)/(5). Similar to the conventional two stage Heckman model, the first two stages are estimated jointly while independently of the third stage. Then we extract a pair of correlated IMRs (one for each stage) at each period and insert them into the equation of the third stage. 
We calculate the standard IMR from the first stage Zombie equation (upper Equation in Model 6) at period 1 since the first event has a marginal probability so that:

$$
I M R_{Z_{Z O M}}=\left\{\begin{array}{l}
\frac{\phi\left(X_{i 1}^{\prime} \hat{\alpha}+Z_{i 1}^{\prime} \hat{\gamma}\right)}{\Phi\left(X_{i 1}^{\prime} \hat{\alpha}+Z_{i 1}^{\prime} \hat{\gamma}\right)} \text { if } Z O M=1 \\
\frac{-\phi\left(X_{i 1}^{\prime} \hat{\alpha}+Z_{i 1}^{\prime} \hat{\gamma}\right)}{1-\Phi\left(X_{i 1}^{\prime} \hat{\alpha}+Z_{i 1}^{\prime} \hat{\gamma}\right)} \text { if } Z O M=0
\end{array}\right.
$$

where $\hat{\alpha}, \hat{\lambda}$ are estimated from the previous bivariate Probit model.

However, the errors between the first two stages are correlated, thus applying normal IMR for the ongoing events $\left(I M R_{C S R_{-} R_{t=1}}, I M R_{Z_{Z_{t}}=2}, I M R_{C S R_{-} R_{t=2}}, \ldots, I M R_{Z M_{t=T}}, I M R_{C S R_{-} R_{t}=T}\right)$ might lead to inconsistent results. In fact, the IMR refers to the expectation of the truncated random variable, however, note that these quantities are conditioned on previous events. Thus, we obtain each conditional truncated expectation via simulations using the same framework of the GHK method. To illustrate, the second stage IMR from $C S R \_R$ equation (lower equation in Model 6) at period 1 could be obtained using:

$$
I M R_{C S R_{-} R_{t=1}} \approx \frac{1}{R} \sum_{r=1}^{R}\left[\hat{a}_{21} \eta_{1}^{* r}+\hat{a}_{22} \eta_{2}^{* r}\right]
$$

where $\hat{a}_{s}$ are the Cholesky components of the estimated $\Sigma$ from previous bivariate Probit model and $\eta_{2}^{* r}$ is $r^{\text {th }}$ random draw generated from the truncated standard normal distribution with upper truncation point (according to the occurred event, here refers to the fact $\left.X_{i 1}^{\prime} \hat{\beta}+Z O M_{i 1} \hat{\lambda}+\hat{a}_{21} \eta_{1}^{*}+\hat{a}_{22} \eta_{2}^{*}>0\right)$ at $\frac{X_{i 1}^{\prime} \hat{\beta}+Z O M_{i 1} \hat{\lambda}-\hat{a}_{21} \eta_{1}^{* r}}{\hat{a}_{22}}$. It can be simulated in the same way as for $\eta_{1}^{* r}$. Similarly, we have IMRs for the two stage events at each $t$ for all $t>1$ :

$$
\begin{gathered}
I M R_{\mathrm{ZOM}_{t}} \approx \frac{1}{R} \sum_{r=1}^{R}\left[\hat{a}_{2 t-1,1} \eta_{1}^{*_{r}}+\hat{a}_{2 t-1,2} \eta_{2}^{*_{r}}+\ldots+\hat{a}_{2 t-1,2 t-1} \eta_{2 t-1}^{*_{r}}\right] \\
I M R_{\mathrm{CSR}_{-} R_{t}} \approx \frac{1}{R} \sum_{r=1}^{R}\left[\hat{a}_{2 t, 1} \eta_{1}^{*_{r}}+\hat{a}_{2 t, 2} \eta_{2}^{*_{r}}+\ldots+\hat{a}_{2 t, 2 t} \eta_{2 t}^{*_{r}}\right]
\end{gathered}
$$

Once we have the two IMRs for each $t$, we insert them into the third stage equations to measure CSRD_S (Model 4) and CSRF_S (Model 5) accordingly.

We also consider fixed effect in the third stage because that could further mitigate the endogeneity concern by eliminating the potential bias caused by unobserved time-invariant endogeneity. However, our main explanatory variable "being zombie" has very small within-person variance. Specifically, the between-to-within individual variance ratio is 6.13 , which is much higher than the critical value as discussed in Plümper and Troeger (2007). This means zombie status barely changes over time for a given individual so that applying a conventional fixed effect approach returns only the within-person switching effect of zombie status rather than its between-person effect. To reach both ends, we use the fixed effect vector decomposition (FEVD) method proposed by Boyce (2010):

Step1: A FE regression of CSRD_S/CSRF_S over time-variant variables, e.g. SIZE, ROA, LEV, $T Q, C F O$ to obtain residuals.

Step2: Regress the first step residuals over time-invariant or low within-person varying variation variables, e.g. ZOM, FIRST, BOARD, MANSHR, DUAL, ST, etc., and obtain the residuals as the "true unobserved component" (Res2) that is orthogonal to zombie status and is almost constant for a given firm.

Step3: Estimate the full model by adding the previously obtained unobserved component (Res2) to control for time-invariant individual effect and thus to reduce the endogeneity risk.

We report the third stage estimates in Table 6. In the Column (1) for CSRD_S equation, we see that being zombie has a significant positive effect which is different from the naive model result but 
still consistent with Hypothesis 2, while it has a negative sign in Column (2) for the CSRF_S equation which is the same as in the naive model.

The two IMR terms are both significant in the CSRD_S equation (Model 4) which justifies the necessity of correcting for endogeneity and selection bias. In CSRF_S equation (Model 5), endogeneity of zombie status is an issue. On the contrary, selection bias is less of a problem in the CSRF_S equation. We use this subsample not because of CSRF observability, but because we want to focus on the comparison between zombie and non-zombie firms when releasing CSR reports. This indicates sample selection in Model (5) does not cause any selectivity bias.

The insertion of the last correction term obtained using FEVD process allows us to further correct endogeneity bias. This refers to the Res 2 terms. We found a significant time-invariant individual effect while it is again less significant in the right panel.

Table 6

The third stage results (CSRD_S and CSRF_S equations) using IV

\begin{tabular}{lcc} 
& $(1)$ & $(2)$ \\
ZOM & CSRD_S & CSRF_S \\
& $2.432^{* * *}$ & $-0.126^{* * *}$ \\
IMR1 & $(0.663)$ & $(0.037)$ \\
& $-12.047^{* * *}$ & $1.193^{* * *}$ \\
IMR2 & $(0.720)$ & $(0.040)$ \\
& $-1.114^{* * *}$ & $-0.030^{*}$ \\
Res2 & $(0.325)$ & $(0.018)$ \\
& $0.754^{* * *}$ & $0.002^{*}$ \\
Other controls & $(0.015)$ & $(0.001)$ \\
Year effects & Yes & Yes \\
Industry effects & Yes & Yes \\
\hline Observations & Yes & Yes \\
Adjusted $R^{2}$ & 3617 & 3617 \\
F test & 0.589 & 0.096 \\
\hline Notes: Robust standard errors in parentheses; ${ }^{*} \mathrm{p}<0.1,{ }^{* *} \mathrm{p}<0.05,{ }^{* * *} \mathrm{p}<0.01$.
\end{tabular}

So far, after controlling for multiple endogeneity and selection issues, our empirical evidence supports Hypothesis 2 consistently.

\subsubsection{Endogeneity correction without exclusion restrictions}

Our instrumental variable choice be doubtful as in the same remark raised by Lennox et al. (2011). Therefore, we turn to parametric heteroscedasticity to achieve identification?. Analogous approaches have been discussed in recent econometric literature, see for instance Klein and Vella (2010) and Farré et al. (2013).

Since our first two stages are Probit models, heterogeneity could be introduced directly by resealing the variance of the error terms, using a general form of heteroscedasticity such as:

$$
\begin{gathered}
\sigma_{z d}^{2}+\sigma_{v}^{2}=\exp \left(W_{i t} \delta_{z}\right) \\
\sigma_{c d}^{2}+\sigma_{\varepsilon}^{2}=\exp \left(W_{i t} \delta_{c}\right)
\end{gathered}
$$

7 The identification based on heteroscedasticity avoids the risk of invalid instruments and meanwhile using pure statistical information brings practical accessibility in the absence of trustful exclusion restriction restrictions. 
where $W_{i t}$ is a set of observed variables explaining residual dispersion and $\delta$ is a vector of parameters. In our empirical analysis, we chose PEMPLOYEE, SIZE, LEV, AGE to model heteroscedasticity. The main estimated parameters are given in Table 7.

After considering the parametric heteroscedasticity, the share of random effects variances has dropped dramatically ${ }^{8}$ compared to Table 5 (reduced from 0.590 to 0.231 ) but all are still significant. The ZOM effect in the CSR_R equation remains negative and significant. The significant positive effect of $Z O M$ for the CSRD_S equation vanishes but is still positive, while the effect for the CSRF_S keeps the same. So, our previous results using IV were fragile, and the results estimated using heteroscedasticity are more reliable. However, parametric heteroscedasticity may cause distributional misspecification error, we shall further test the robustness of our results in the next subsection.

Table 7

Endogeneity correction without exclusion restrictions

\begin{tabular}{|c|c|c|c|}
\hline & (1) & $(2)$ & (3) \\
\hline & CSR_R & CSRD_S & CSRF_S \\
\hline \multirow[t]{2}{*}{$\mathrm{ZOM}$} & $-0.384^{* * *}$ & 0.301 & $-0.139^{* * *}$ \\
\hline & $(0.021)$ & $(0.529)$ & $(0.029)$ \\
\hline Other controls & Yes & Yes & Yes \\
\hline Year effects & Yes & Yes & Yes \\
\hline Industry effects & Yes & Yes & Yes \\
\hline \multirow[t]{2}{*}{$\rho \sigma_{v} \sigma_{\varepsilon}$} & $0.231^{* * *}$ & & \\
\hline & $(0.06)$ & & \\
\hline \multirow[t]{2}{*}{$\sigma_{z d}$} & $0.003^{* * *}$ & $\sigma_{c d}$ & $0.207^{* * *}$ \\
\hline & $(0.000)$ & & $(0.010)$ \\
\hline Likelihood & -6501.39 & & \\
\hline Adjusted $R^{2}$ & & 0.583 & 0.096 \\
\hline
\end{tabular}

\subsection{Robustness checks}

In order to test the validity of our results, we conduct three checks in the following section. These include considering: (i) propensity score matching (PSM); (ii) alternative measurement of zombie firms; (iii) alternative measurement of CSRF.

\subsubsection{PSM methodology}

We apply the PSM methodology to get a paired sample for regression and to estimate the average treatment effect on the treated (ATT) between zombie and non-zombie groups.

The first step estimates the "likelihood of receiving treatment", that is, the propensity score (PS). In the full sample of Model (3), the zombie firms are in the treatment group and the non-zombie firms are in the control group. In the subsample of Models (4) and (5), the zombie firms who released CSR reports are in the treatment group, and the non-zombie firms of released CSR reports are in the control group. We start with a logistic regression for Model (6) using full sample and subsample respectively, and obtained PS under two samples.

The second step matches the zombie firms to their control pairs based on PS. We use nearest-neighbor matching to obtain two sets of paired samples: paired sample under full sample to test Model (3) and paired sample under subsample to test Models (4) and (5). As shown in Fig. 2 (full sample) and Fig. 3 (subsample), the kernel densities of zombie and non-zombie firms are quite different before matching while they become very close after matching, indicating that the characteristics of the variables in the two groups are similar. 


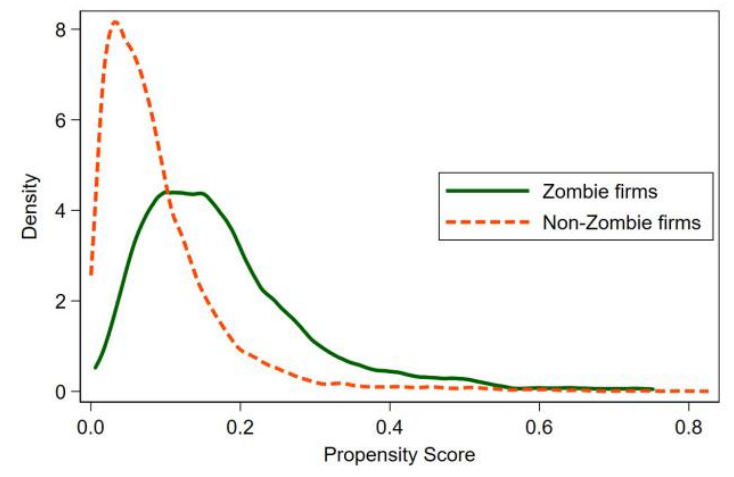

(a)

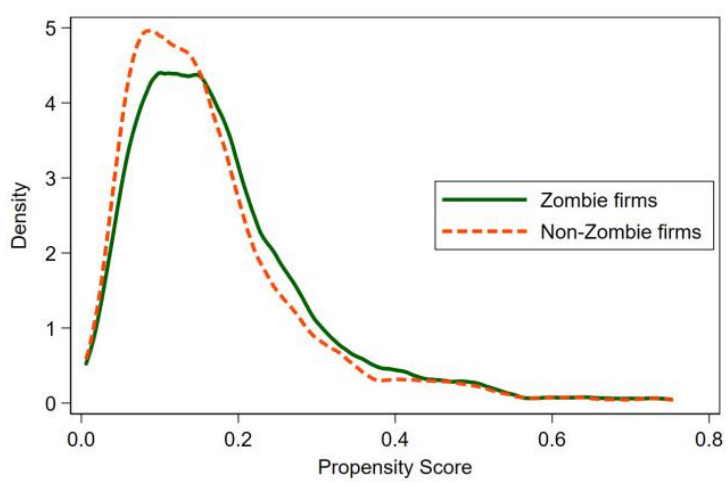

(b)

Fig. 2. Kernel density of zombie firms and non-zombie firms under full sample. (a) before matching; (b) after matching.

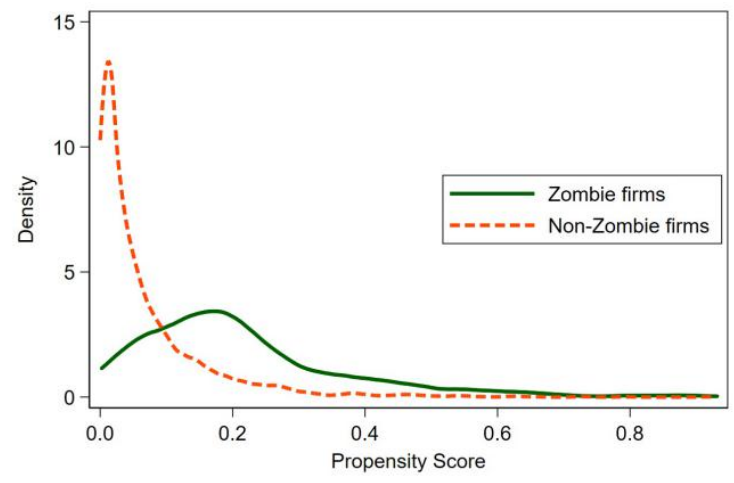

(a)

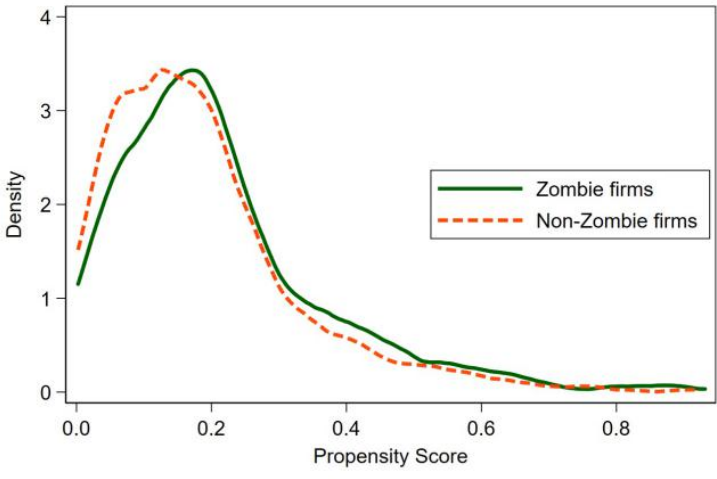

(b)

Fig. 3. Kernel density of zombie firms and non-zombie firms under CSR reports released subsample. (a) before matching; (b) after matching.

The final step estimates Models (3), (4), and (5) using only paired samples. Using the paired sample obtained under the full sample, we estimate Model (3) using Probit, as shown in Column (1) of Table 8. Using the paired sample obtained under the subsample releasing CSR reports, we estimate the Models (4) and (5), as shown in Columns (2) and (3) of Table 8. Thus, when we focus on non-zombie firms that have similar characteristics to zombie firms, we find results which are consistent with those reported in Table 4.

\section{Table 8}

Robustness check: propensity score matching methodology

\begin{tabular}{lccc}
\hline & (1) Probit & (2) OLS & (3) OLS \\
ZOM & CSR_R & CSRD_S & CSRF_S \\
& $-0.153^{* * *}$ & -0.359 & $-0.113^{* * *}$ \\
Other controls & $(0.055)$ & $(0.747)$ & $(0.035)$ \\
Year effects & Yes & Yes & Yes \\
Industry effects & Yes & Yes & Yes \\
\hline Observations & Yes & Yes & Yes \\
Adjusted/Pseudo $R^{2}$ & 3326 & 709 & 709 \\
F/Chi2 test & 0.195 & 0.336 & 0.170 \\
\hline Notes: Robust standard erors & 728.765 & 11.753 & 4.276 \\
\hline
\end{tabular}

Notes: Robust standard errors in parentheses; ${ }^{*} \mathrm{p}<0.1{ }^{* *} \mathrm{p}<0.05,{ }^{* * *} \mathrm{p}<0.01$. 
In addition, we also used the nearest neighbor matching, radius matching, and nuclear matching to calculate the ATT of zombie firms. The differences of the CSR_R between zombie firms and non-zombie firms are all significant in both unmatched and matched cases while the differences of CSRD_S between zombie firms and non-zombie firms are not significant. However, the CSRF_S of zombie firms is significantly lower than non-zombie firms in both unmatched and matched cases. The ATT differences obtained by PSM are less prone to endogenous risks and not sensitive to the functional form and the results here validate our previous empirical evidence and support our hypothesis.

Table 9

Robustness checks: ATT calculated by PSM

\begin{tabular}{|c|c|c|c|c|c|c|c|}
\hline & Method & Sample & Treated & Controls & Differ & S.E. & $\mathrm{T}$ test \\
\hline \multirow{4}{*}{$\begin{array}{l}\sim^{\prime} \\
\frac{\sigma^{\prime}}{w}\end{array}$} & \multicolumn{2}{|c|}{ Unmatched } & 0.220 & 0.294 & -0.074 & 0.013 & -5.65 \\
\hline & nearest & ATT & 0.220 & 0.255 & -0.035 & 0.016 & -2.25 \\
\hline & radius & ATT & 0.221 & 0.256 & -0.035 & 0.014 & -2.57 \\
\hline & nuclear & ATT & 0.220 & 0.259 & -0.039 & 0.013 & -3.02 \\
\hline \multirow{4}{*}{ 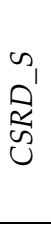 } & \multicolumn{2}{|c|}{ Unmatched } & 38.027 & 37.778 & 0.250 & 0.771 & 0.32 \\
\hline & nearest & ATT & 38.027 & 38.170 & -0.143 & 0.958 & -0.15 \\
\hline & radius & ATT & 37.462 & 38.165 & -0.703 & 0.952 & -0.74 \\
\hline & nuclear & ATT & 38.027 & 38.043 & -0.015 & 0.821 & -0.02 \\
\hline \multirow{4}{*}{$\begin{array}{l}w_{1} \\
\frac{1}{2} \\
v\end{array}$} & \multicolumn{2}{|c|}{ Unmatched } & 0.945 & 1.021 & -0.075 & 0.029 & -2.62 \\
\hline & nearest & ATT & 0.945 & 1.061 & -0.115 & 0.039 & -2.97 \\
\hline & radius & ATT & 0.953 & 1.073 & -0.120 & 0.033 & -3.67 \\
\hline & nuclear & ATT & 0.945 & 1.039 & -0.093 & 0.028 & -3.38 \\
\hline
\end{tabular}

\subsubsection{Alternative measures to proxy for zombie firms}

No matter which method is used, the identification of zombies and non-zombies may still be problematic. The probability of identification errors is greater when the characteristics of zombie and non-zombie firms are similar. When the subsidized interest rate is around 0 , the characteristics of zombies and non-zombies are relatively close. A small error calculated by the subsidized interest rate near the value of 0 may cause the sign change of GAP which leads to misidentification. In order to overcome this type of error, we use "fuzzy set" method proposed by Caballero et al. (2008). As shown by the member function of Equation (20), we take an interval $\left(d_{1}, d_{2}\right)$ around the value of 0 . When GAP belongs to $\left(d_{1}, d_{2}\right)$, the firms are between zombies and non-zombies, which is a fuzzy set of zombie firms. A clear zombie firms when GAP is less than $d_{1}$, a clear non-zombie firms when GAP is greater than $d_{2}$. We remove this fuzzy set and only keep crisp zombies or non-zombies, which can reduce the possibility of misclassification. Columns (1) - (3) of Table 10 are the results of deleting the observations corresponding to $G A P \in(0,0.005)$, Columns (4) - (6) of Table 10 are the results of deleting the observations corresponding to $G A P \in(-0.0025,0.0075)$.

$$
Z\left(G A P ; d_{1}, d_{2}\right) \begin{cases}1 & \text { if } G A P<d_{1} \\ \frac{d_{2}-G A P}{d_{2}-d_{1}} & \text { if } d_{1} \leq G A P \leq d_{2} \text { where } d_{1} \leq 0 \leq d_{2} \\ 0 & \text { if } G A P>d_{2}\end{cases}
$$

Table 10

Robustness check: delete fuzzy zombie firms

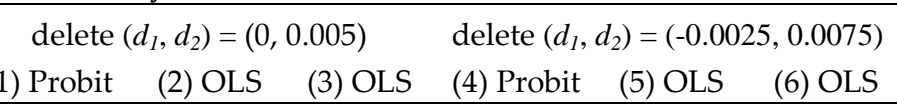




\begin{tabular}{lcccccc}
\hline \multirow{2}{*}{ ZOM } & CSR_R & CSRD_S & CSRF_S & CSR_R & CSRD_S & CSRF_S \\
& $-0.138^{* * *}$ & -0.728 & $-0.110^{* * *}$ & $-0.138^{* * *}$ & -0.562 & $-0.116^{* * *}$ \\
Other controls & $(0.048)$ & $(0.648)$ & $(0.026)$ & $(0.050)$ & $(0.649)$ & $(0.027)$ \\
Year effects & Yes & Yes & Yes & Yes & Yes & Yes \\
Industry effects & Yes & Yes & Yes & Yes & Yes & Yes \\
\hline Observations & Yes & Yes & Yes & Yes & Yes & Yes \\
Adjusted/Pseudo $R^{2}$ & 0.193 & 0.338 & 0.173 & 0.188 & 0.329 & 0.173 \\
F/Chi2 test & 2842.260 & 42.053 & 16.090 & 2601.007 & 38.270 & 15.130 \\
\hline
\end{tabular}

Notes: Robust standard errors in parentheses; ${ }^{*} \mathrm{p}<0.1,{ }^{* *} \mathrm{p}<0.05,{ }^{* * *} \mathrm{p}<0.01$.

We still found consistent conclusions after using these alternative definitions of zombie firms.

\subsubsection{Alternative measures to proxy for CSRF}

The measurement of CSRF is calculated using the data from the "statement of cash flows" prepared on the "cash basis of accounting". Although this method can avoid the defects that the data is easily manipulated by the management team under the "accrual basis of accounting", there are also shortcomings that cannot fully reflect the CSRF due to the limitation of data availability. For example, the CSRF for the consumer cannot be reflected in the "statement of cash flows" (He, Z. et al., 2018). Therefore, in combination with the "cash basis of accounting" and the "accrual basis of accounting", we use the data in the "balance sheet", "income statement" and "statement of cash flows" to correct the measurement of CSRF.

First, we have increased consumer social responsibility in existing measurements, as measured by operating costs in the "income statement". In addition, we have also noticed that the Chinese government often refunds some taxes and fees to enterprises through tax incentives, so the CSRF should deduct these refunds. Therefore, we amend the indicators of the CSRF, specifically plus operating costs and then subtract the tax refunds. Then, using this as the explanatory variable, the Model (5) is re-estimated, and the results are as shown in Column (1) of Table 11, which is consistent with the foregoing discussion.

The concept of "social contribution per share" (SCPS) is proposed in the "Notice on Strengthening the Social Responsibility of Listed Companies" issued by the SSE in May 2008. On the basis of the earnings per share (EPS) created for shareholders, the SCPS increases the value created for other stakeholders, such as taxes created for the state, wages paid to employees, interest paid to creditors, external donations, and deduct other social costs caused by environmental pollution. SSE advocates that listed companies actively implement SCPS, which can help the public to understand more fully the true value that the company creates for its shareholders, employees, customers, creditors, communities and society as a whole. We use the SCPS to measure the CSRF. Specifically, $\mathrm{SCPS}=$ (net income + income tax expense + business tax and surcharge + cash paid for employees + year-on-year net increase in "payroll payables" + financial expenses + donations - sewage charges and cleaning fee) / Average of the total number of shares at the beginning and end of the period. Column (2) in Table 11 is the result of measuring CSRF_S with SCPS, which also shows that the CSRF of zombies is still significantly lower than that of non-zombies.

Table 11

Robustness check: alternative measures to proxy for CSRF_S

\begin{tabular}{lcc}
\hline & $(1)$ modified CSRF & $(2)$ SCPS \\
ZOM & $-0.198^{* * *}$ & $-0.873^{* * *}$ \\
Other controls & $(0.040)$ & $(0.056)$ \\
Year effects & Yes & Yes \\
Industry effects & Yes & Yes \\
\hline Observations & Yes & Yes \\
\hline
\end{tabular}


Notes: Robust standard errors in parentheses; ${ }^{*} \mathrm{p}<0.1,{ }^{* *} \mathrm{p}<0.05,{ }^{* * *} \mathrm{p}<0.01$; Ordinary least square is applied here.

\section{Further analysis}

In this section, we further investigate the degree of inconsistence due to heterogeneity using different comparison group definitions. However, we do not further discuss any potential endogeneity issues.

\subsection{How does external support affect CSRD and CSRF of zombie firms?}

External support not only brings more resources to the zombie firms, but also creates more relaxed institutional environment for zombie firms. In order to test the impact of external support on the CSRD and CSRF of zombie firms, we add the interaction between zombie firms and external support in Models (4) and (5). Specifically, "governmental support" is measured by the natural logarithm of the government subsidy received by firms, and is recorded as G_SUB; "bank support" is measured by the subsidized interest rate enjoyed by firms, that is, the opposite figure of GAP calculated within the CHK model, and is recorded as $B \_S U B$.

Columns (1) and (2) in Table 12 are the results of the regression of CSRD_S and CSRF_S on $Z O M^{*} G_{-} S U B$, respectively. The coefficient of $Z O M^{*} G_{-} S U B$ is not significant in the regression of CSRD_S, but is significantly positive in the regression of CSRF_S. This shows that zombies receiving government subsidies have indeed fulfilled more CSR, but still lag non-zombie firms. The Chinese government, especially local governments, often provide subsidies for zombie firms in a variety of ways, such as "stable employment", "employee resettlement", "industry upgrade", "technical transformation", and "energy saving and emission reduction". Although these subsidies appear to be legitimate and reasonable in form, they are still being questioned by the investor, market, and public. In response to these doubts, zombie firms have to fulfill some CSR, which in turn provides an excuse to receive continuous government subsidies. However, the zombie firms facing bankruptcy use most of the subsidies to maintain their survival. They can only use the remaining small subsidies for CSR activities such as "relocation of workers" and "energy saving and emission reduction". By maintaining the same level of CSRD as other non-zombies, zombies can ease the legitimacy pressure without having to bear the cost of actually fulfilling CSR. Therefore, although the CSRF of zombie firms will increase with the receipt of government subsidies, it is still lower than non-zombie firms, and its words and actions are still inconsistent.

Columns (3) and (4) in Table 12 are the results of the regression of the $Z O M^{*} B \_S U B$ to CSRD_S and CSRF_S, respectively. The coefficients of $Z O M^{*} B \_S U B$ are both not significant in the two regressions. This shows that bank subsidies have not affected the CSRD and CSRF of zombie firms. Unlike government subsidies, bank interest subsidies are interest reduction, which only reduces the outflow of resources from zombie firms, and there are no incremental resources flowing into zombie firms. Bank interest subsidies are also more concealed than government subsidies. Therefore, taxpayers and other publics are less concerned about the interest subsidies received by zombie firms. This puts the zombie firms under less pressure to enforce CSR. In the absence of resource inflows and less legitimacy pressure, zombie firms tend to manipulate a responsible image through exaggerated CSRD, while not actually fulfill more CSR.

Table 12

The impact of external support on CSRD and CSRF

\begin{tabular}{lcccccc}
\hline & $(1)$ & $(2)$ & $(3)$ & $(4)$ & $(5)$ & $(6)$ \\
COM & CSRD_S & CSRF_S & CSRD_S & CSRF_S & CSRD_S & CSRF_S \\
& $-4.244^{*}$ & $-0.254^{* * *}$ & -0.531 & $-0.103^{* * *}$ & 0.318 & $-0.207^{* * *}$ \\
ZOM & $(2.321)$ & $(0.094)$ & $(0.700)$ & $(0.025)$ & $(1.009)$ & $(0.047)$
\end{tabular}




\begin{tabular}{lcccccc} 
G_SUB & $(0.150)$ & $(0.006)$ & & & & \\
& -0.025 & $0.005^{* * *}$ & & & & \\
ZOM*B_SUB & $(0.060)$ & $(0.002)$ & & & & \\
& & & 2.667 & 0.146 & & \\
B_SUB & & & $(6.124)$ & $(0.230)$ & & \\
& & & $2.791^{*}$ & $-0.322^{* * *}$ & & \\
ZOM ${ }^{*}$ NATURE & & $(1.532)$ & $(0.097)$ & & -1.259 & $0.130^{* * *}$ \\
& & & & & $(1.236)$ & $(0.053)$ \\
NATURE & & & & $0.880^{*}$ & $-0.065^{* * *}$ \\
& & & & & $(0.451)$ & $(0.021)$ \\
Other controls & Yes & Yes & Yes & Yes & Yes & Yes \\
Year effects & Yes & Yes & Yes & Yes & Yes & Yes \\
Industry effects & Yes & Yes & Yes & Yes & Yes & Yes \\
\hline Observations & 3617 & 3617 & 3617 & 3617 & 3617 & 3617 \\
Adjusted $R^{2}$ & 0.336 & 0.181 & 0.337 & 0.183 & 0.336 & 0.180 \\
F test & 42.567 & 16.325 & 42.705 & 16.681 & 43.627 & 16.588 \\
\hline
\end{tabular}

Notes: Robust standard errors in parentheses; ${ }^{*} \mathrm{p}<0.1,{ }^{* *} \mathrm{p}<0.05,{ }^{* * *} \mathrm{p}<0.01$; Ordinary least square is applied here.

\subsection{Does ownership affect CSRD and CSRF of zombie firms?}

As given in Table 3, the proportion of state-owned zombie firms in the full sample is $57.7 \%$, but this percentage increased to $78.9 \%$ in the subsample. The regression results of Model (3) in Table 4 indicate that SOEs are more inclined to release CSR reports. Then, for state-owned zombie firms that release CSR reports, how is their CSRF and CSRD different from the non-state-owned zombie firms?

We added the interaction of SOEs and zombie firms in Models (4) and (5). The results of Column (5) in Table 12 show that the coefficient of ZOM*NATURE is not significant. This shows that the CSRD of state-owned zombies and non-state-owned zombies are not significantly different, and zombie firms are basically the same level as non-zombie firms. The results of Column (6) in Table 12 show that the coefficient of ZOM*NATURE is significantly positive. This shows that the CSRF of state-owned zombies is significantly higher than non-state-owned zombies, but still lower than non-zombies $(-0.207+0.131<0)$. On the whole, compared with non-state-owned zombies, state-owned zombies have indeed assumed more CSR, and their "words" and "actions" deviations have decreased, but their CSRD and CSRF are still inconsistent.

\subsection{Does CSR assurance affect CSRD and CSRF of zombie firms?}

The inconsistency between the CSRD and CSRF indicates that the credibility of CSR reports is poor. This "symbolic" or "labelling" CSRD has been well known to stakeholders (Velte and Stawinoga, 2017) and has attracted the regulators' attention. In China, SSE and SZSE both encourage companies to conduct independent third-party assurance of CSR reports (CSRA) to improve the credibility of CSR reports. As an effective monitoring mechanism, CSRA can improve the credibility of CSR reports, and may alleviate the inconsistency between CSRD and CSRF.

To analyze this question, we divide the subsample into two groups: the CSRA group and non-CSRA group. We use the two samples of the CSRA group and non-CSRA group to estimate Models (4) and (5), respectively. In the results of the non-CSRA group in Columns (1) and (2) of Table 13, there is no significant difference in CSRD_S of zombie firms relative to non-zombie firms, but the CSRF_S is significantly lower, which indicates that the inconsistency in the CSRD and CSRF of zombie firms still exists. In the results of the CSRA group in Columns (3) and (4) of Table 13, the CSRD_S of zombie firms is significantly lower than that of non-zombie firms, which indicates that the CSRD of zombie firms is lower than non-zombie firms. To summarize, CSRA can somewhat restrain the exaggerated CSRD of zombie firms, improve the credibility of CSR reports, and make 
the "words" and "actions" of zombie firms less inconsistent (Pflugrath et al., 2011; Simnett et al., 2009).

Table 13

The impact of CSR assurance on CSRD and CSRF

\begin{tabular}{lcccc} 
& $(1)$ & $(2)$ & $(3)$ & \\
& Non-CSRA group & \multicolumn{2}{c}{ CSRA group } \\
ZOM & CSRD_S & CSRF_S & CSRD_S & CSRF_S \\
& -0.485 & $-0.107^{* * *}$ & $-5.408^{* *}$ & -0.141 \\
Other controls & $(0.619)$ & $(0.025)$ & $(2.476)$ & $(0.095)$ \\
Year effects & Yes & Yes & Yes & Yes \\
Industry effects & Yes & Yes & Yes & Yes \\
\hline Observations & Yes & Yes & Yes & 347 \\
Adjusted $R^{2}$ & 3534 & 3534 & 347 & 0.203 \\
F test & 0.322 & 0.178 & 0.595 & 3.989 \\
\hline Notes: Robust standard errors in parentheses; ${ }^{*} \mathrm{p}<0.1,{ }^{* *} \mathrm{p}<0.05,{ }^{* * *} \mathrm{p}<0.01 ;$ Ordinary least square is applied \\
here. & 43.788 & &
\end{tabular}

\section{Discussion and conclusions}

In literature, most related studies do not distinguish between CSRD and CSRF, and often conduct research assuming they are consistent. However, the inconsistency between CSRD and CSRF is widespread in business practice. Although zombie firms have negative consequences for economic growth, the government, especially the local governments often help zombie firms to survive by claiming that zombie firms have assumed more CSR. Are Zombie firms fulfilling adequate CSR correspondingly? Are their CSRD and CSRF consistent or not?

According to the comprehensive analysis of multiple theories, the institutional environment of external support changes the power of the stakeholders of zombie firms and reduces the legitimacy pressure, which makes zombie firms less willing to release CSR reports. However, once zombie firms release CSR reports, they may engage in hypocritical behavior with inconsistency behavior between CSRD and CSRF. First, using a panel data set of 13,008 Chinese-listed firm-year observations from 2009 to 2016, we found that zombie firms are less willing to release standalone CSR reports than non-zombie firms. Second, using panel data from 3617 Chinese-listed firm-year observations who released CSR reports, we found that there is no significant difference in CSRD between zombie and non-zombie firms, but the CSRF of zombie firms is significantly lower than non-zombie firms. This shows that CSRD and CSRF of zombie firms are relatively inconsistent, which provides supplementary perspective concerning zombie firms for hypocritical CSR theory of Fassin and Buelens (2011).

We apply a range of methods to overcome the endogeneity and our results are robust. First, we use the triangular bivariate Probit model to overcome the endogeneity of being zombie firms to the release of CSR reports, and consistently find that zombie firms are less willing to release CSR reports. Second, using the previous two stages estimated in the first step, we build up a three-stage Heckman model to simultaneously control for the endogeneity of being zombie firms and for the selection bias of releasing CSR reports. It validates inconsistency between CSRD and CSRF of zombie firms. Third, we also suggest to use statistical identification for endogenous variable when exclusion restriction condition does not meet. Fourth, the regression results of the paired sample obtained by the PSM method and the ATT both support our hypothesis. Fifth, using alternative measurement of zombie or CSRF both lead to the same conclusions.

We further discussed the reasons for inconsistency between CSRD and CSRF of zombie firms. First, we found that the inconsistency between CSRD and CSRF of zombie firms could be alleviated with the increase of government subsidies while not suppressed. Bank subsidies had no significant effect on the inconsistency. Second, compared with non-state-owned zombies, state-owned zombies 
have indeed assumed more CSR, and their "words" and "actions" deviations have decreased, but their CSRD and CSRF are still inconsistent. Third, we found that CSRA as an external oversight mechanism does restrains the inconsistency between CSRD and CSRF of zombie firms.

So far, we have two important implications. First, the combination of NIT, ST, and LT theories can better explain the causes of hypocritical CSR. The imperfect institutional environment has changed the stakeholders' power and firms' legitimacy pressure, and at the same time has provided the opportunity for false disclosure. The hypocritical CSR can blind stakeholders, so that the hypocrite could enjoy the benefits of CSR without bearing the cost, such as reducing the pressure of legitimacy, obtaining economic benefits, etc. The interests of stakeholders and companies that are truly socially responsible will be harmed. The worst result is that stakeholders who cannot distinguish the true from the false can be extremely distrustful of CSR, and enterprises that truly engage in CSR could not obtain corresponding benefits, which will eventually lead to the shrinking or even disappearance of CSR. When enterprises are unwilling to fulfill CSR activities, the sustainable development of society will also be infringed. This provides better theoretical guidance for suppressing hypocritical CSR, promoting real CSR activities and achieving sustainability.

We also found some practical policy implications. First, the hypocritical CSR of zombie firms indicates that the government's argument for helping zombie firms is untenable. Chinese central government should urge and ensure that local governments fully implement policies to clean up and dispose of zombie firms, and prevent local governments from using various excuses to help zombie firms to survive. Second, along with the economic transformation, continuous improvement of the institutional environment is an important path to promote CSR and sustainable development. One of the typical characteristics of the transitional economy is the incompleteness of the institutional environment and its constant transformation. As a transitional country with the largest population in the world, the incompleteness of China's institutional environment is inevitable, but reform can continuously correct the flawed institutional environment. China should constantly improve the CSRF and CSRD system in light of the problems exposed in CSR practices, such as formulating more specific and enforceable CSRF and CSRD guidelines, establishing third-party supervision and restraint mechanisms such as CSRA, and introducing appropriate penalties for false CSRD.

In the end, we notice that current investigation still leaves one fundamental question: what are the motivations and reasons for zombie firms to choose between silent or hypocritical CSR activities? We have argued that when the legitimacy pressure of external support is relatively high, the zombie firms may release standalone CSR reports to lie. However, the change of legitimacy pressure of external support for zombie firms might attribute to the complex game among multiple stakeholders, such as the central government, the public, public investors, local governments, banks, and zombie firms. We believe that it is extremely challenging to answer such a question empirically and it deserves more investigations in the future.

\begin{abstract}
Acknowledgments: We would like to show our sincere gratitude to the Associate Editor (Dr. Mattias Lindahl) and the five anonymous reviewers whose comments and suggestions greatly improved the quality of this paper. The authors gratefully acknowledge the financial support from the National Natural Science Foundation of China (No. 71764008), the Ministry of Education of Humanities and Social Science Project (No. 17YJC790046), Shaanxi Social Science Planning Fund Program (No. 2019D010) and Shaanxi Province Department of Education special scientific research project (No. 17JK0741). The remaining errors are solely ours.
\end{abstract}

Conflicts of Interest: The authors declare no conflict of interest.

\title{
References
}

Adegbite, E., Guney, Y., Kwabi, F., Tahir, S., 2019. Financial and corporate social performance in the UK listed firms: the relevance of non-linearity and lag effects. Review of Quantitative Finance and Accounting, 1-54. 
Ali, W., Frynas, J.G., Mahmood, Z., 2017. Determinants of corporate social responsibility (CSR) disclosure in developed and developing countries: A literature review. Corporate Social Responsibility and Environmental Management 24(4), 273-294.

Arena, M., Azzone, G., Mapelli, F., 2018. What drives the evolution of Corporate Social Responsibility strategies? An institutional logics perspective. Journal of Cleaner Production 171, 345-355.

Banerjee, R., Gupta, K., McIver, R., 2019. What matters most to firm-level environmentally sustainable practices: Firm-specific or country-level factors? Journal of Cleaner Production 218, 225-240.

Banerjee, R., Hofmann, B., 2018. The rise of zombie firms: causes and consequences. BIS Quarterly Review September.

Belal, A.R., Cooper, S., 2011. The absence of corporate social responsibility reporting in Bangladesh. Critical Perspectives on Accounting 22(7), 654-667.

Bhattacharya, C.B., Sen, S., 2004. Doing better at doing good: When, why, and how consumers respond to corporate social initiatives. California Management Review 47(1), 9-24.

Bowen, F., Aragon-Correa, J.A., 2014. Greenwashing in corporate environmentalism research and practice: The importance of what we say and do. Sage Publications Sage CA: Los Angeles, CA.

Boyce, C.J., 2010. Understanding fixed effects in human well-being. Journal of Economic Psychology 31(1), 1-16.

Brunsson, N., 1989. The organization of hypocrisy: Talk, decisions and actions in organizations. John Wiley \& Sons.

Caballero, R.J., Hoshi, T., Kashyap, A.K., 2008. Zombie lending and depressed restructuring in Japan. American Economic Review 98(5), 1943-1977.

Cappellari, L., Jenkins, S.P., 2004. Modelling low income transitions. Journal of Applied Econometrics 19(5), 593-610.

Carlos, W.C., Lewis, B.W., 2018. Strategic silence: Withholding certification status as a hypocrisy avoidance tactic. Administrative Science Quarterly 63(1), 130-169.

Castro-González, S., Bande, B., Fernández-Ferrín, P., Kimura, T., 2019. Corporate social responsibility and consumer advocacy behaviors: The importance of emotions and moral virtues. Journal of Cleaner Production 231, 846-855.

Chams, N., García-Blandón, J., 2019. Sustainable or not sustainable? The role of the board of directors. Journal of Cleaner Production 226, 1067-1081.

Davidson, R.H., Dey, A., Smith, A.J., 2018. CEO materialism and corporate social responsibility. The Accounting Review 94(1), 101-126.

de Jong, M.D., van der Meer, M., 2017. How does it fit? Exploring the congruence between organizations and their corporate social responsibility (CSR) activities. Journal of Business Ethics 143(1), 71-83.

Dhaliwal, D.S., Li, O.Z., Tsang, A., Yang, Y.G., 2011. Voluntary nonfinancial disclosure and the cost of equity capital: The initiation of corporate social responsibility reporting. The Accounting Review 86(1), 59-100.

Farré, L., Klein, R., Vella, F., 2013. A parametric control function approach to estimating the returns to schooling in the absence of exclusion restrictions: an 
application to the NLSY. Empirical Economics 44(1), 111-133.

Fassin, Y., 2005. The reasons behind non-ethical behaviour in business and entrepreneurship. Journal of Business Ethics 60(3), 265-279.

Fassin, Y., Buelens, M., 2011. The hypocrisy-sincerity continuum in corporate communication and decision making: A model of corporate social responsibility and business ethics practices. Management Decision 49(4), 586-600.

Fukuda, S.i., Nakamura, J.i., 2011. Why did 'zombie'firms recover in Japan? The World Economy 34(7), 1124-1137.

García-Sánchez, I.-M., Hussain, N., Martínez-Ferrero, J., 2019. An empirical analysis of the complementarities and substitutions between effects of ceo ability and corporate governance on socially responsible performance. Journal of Cleaner Production 215, 1288-1300.

Graafland, J., Mazereeuw-Van der Duijn Schouten, C., 2012. Motives for corporate social responsibility. De Economist 160(4), 377-396.

Gray, R., Kouhy, R., Lavers, S., 1995. Corporate social and environmental reporting: a review of the literature and a longitudinal study of UK disclosure. Accounting, Auditing $\mathcal{E}$ Accountability Journal 8(2), 47-77.

Groza, M.D., Pronschinske, M.R., Walker, M., 2011. Perceived organizational motives and consumer responses to proactive and reactive CSR. Journal of Business Ethics 102(4), 639-652.

Han, S., You, W., Nan, S., 2019. Zombie firms, external support and corporate environmental responsibility: Evidence from China. Journal of Cleaner Production 212, 1499-1517.

He, Q., Li, X., Zhu, W., 2018. Political connection and the walking dead: Evidence from China's privately owned firms. International Review of Economics \& Finance. He, Z., Shen, W., Li, Q., Xu, S., Zhao, B., Long, R., Chen, H., 2018. Investigating external and internal pressures on corporate environmental behavior in papermaking enterprises of China. Journal of Cleaner Production 172, 1193-1211.

Holder-Webb, L., Cohen, J.R., Nath, L., Wood, D., 2009. The supply of corporate social responsibility disclosures among US firms. Journal of Business Ethics 84(4), 497-527.

Hoshi, T., Kashyap, A.K., 2010. Will the US bank recapitalization succeed? Eight lessons from Japan. Journal of Financial Economics 97(3), 398-417.

Hoshi, T., Kim, Y., 2013. Macroprudential policy and zombie lending in Korea. T. Hoshi and Y. Kim.

Huang, Y., Zhang, Y., 2018. Why zombies can go out: evidence from Chinese manufacturing. Applied Economics Letters 25(12), 853-856.

Jahdi, K.S., Acikdilli, G., 2009. Marketing communications and corporate social responsibility (CSR): marriage of convenience or shotgun wedding? Journal of Business Ethics 88(1), 103-113.

Jaskowski, M., 2015. Should zombie lending always be prevented? International Review of Economics \& Finance 40, 191-203.

Jiang, X., Li, S., Song, X., 2017. The mystery of zombie enterprises-“stiff but deathless". China journal of accounting research 10(4), 341-357. 
John, A., Qadeer, F., Shahzadi, G., Jia, F., 2019. Getting paid to be good: How and when employees respond to corporate social responsibility? Journal of Cleaner Production 215, 784-795.

Kane, E.J., 1987. Dangers of capital forbearance: The case of the FSLIC and “Zombie" S\&Ls. Contemp. Econ. Policy 5(1), 77-83.

Klein, R., Vella, F., 2010. Estimating a class of triangular simultaneous equations models without exclusion restrictions. Journal of Econometrics 154(2), 154-164.

Kwon, H.U., Narita, F., Narita, M., 2015. Resource reallocation and zombie lending in Japan in the 1990s. Review of Economic Dynamics 18(4), 709-732.

Lau, A.K.W., Lee, P.K.C., Cheng, T.C.E., 2018. An empirical taxonomy of corporate social responsibility in China's manufacturing industries. Journal of Cleaner Production 188, 322-338.

Lennox, C.S., Francis, J.R., Wang, Z., 2011. Selection models in accounting research. The Accounting Review 87(2), 589-616.

Liao, L., Lin, T.P., Zhang, Y., 2018. Corporate board and corporate social responsibility assurance: Evidence from China. Journal of Business Ethics 150(1), 211-225.

Liao, P.-C., Shih, Y.-N., Wu, C.-L., Zhang, X.-L., Wang, Y., 2018. Does corporate social performance pay back quickly? A longitudinal content analysis on international contractors. Journal of Cleaner Production 170, 1328-1337.

Liao, P.-C., Xia, N.-N., Wu, C.-L., Zhang, X.-L., Yeh, J.-L., 2017. Communicating the corporate social responsibility (CSR) of international contractors: Content analysis of CSR reporting. Journal of Cleaner Production 156, 327-336.

Lin, X., McKenna, B., Ho, C.M.F., Shen, G.Q.P., 2019. Stakeholders' influence strategies on social responsibility implementation in construction projects. Journal of Cleaner Production 235, 348-358.

Lock, I., Seele, P., 2016. The credibility of CSR (corporate social responsibility) reports in Europe. Evidence from a quantitative content analysis in 11 countries. Journal of Cleaner Production 122, 186-200.

Luo, W., Guo, X., Zhong, S., Wang, J., 2019. Environmental information disclosure quality, media attention and debt financing costs: Evidence from Chinese heavy polluting listed companies. Journal of Cleaner Production 231, 268-277.

Luo, X.R., Wang, D., Zhang, J., 2017. Whose call to answer: Institutional complexity and firms' CSR reporting. Academy of Management Journal 60(1), 321-344.

Margaretha Jastram, S., Klingenberg, J., 2018. Assessing the Outcome Effectiveness of Multi-Stakeholder Initiatives in the Field of Corporate Social Responsibility The Example of the United Nations Global Compact. Journal of Cleaner Production 189, 775-784.

Marquis, C., Qian, C., 2013. Corporate social responsibility reporting in China: Symbol or substance? Organization Science 25(1), 127-148.

Martínez - Ferrero, J., Villarón - Peramato, Ó., García - Sánchez, I.M., 2017. Can Investors Identify Managerial Discretion in Corporate Social Responsibility Practices? The Moderate Role of Investor Protection. Australian Accounting Review 27(1), 4-16. 
McWilliams, A., Siegel, D.S., Wright, P.M., 2006. Corporate social responsibility: Strategic implications. Journal of Management Studies 43(1), 1-18.

Michelon, G., Pilonato, S., Ricceri, F., 2015. CSR reporting practices and the quality of disclosure: An empirical analysis. Critical Perspectives on Accounting 33, 59-78.

Momin, M.A., Parker, L.D., 2013. Motivations for corporate social responsibility reporting by MNC subsidiaries in an emerging country: The case of Bangladesh. The British Accounting Review 45(3), 215-228.

Moneva, J.M., Archel, P., Correa, C., 2006. GRI and the camouflaging of corporate unsustainability, Accounting forum. Taylor \& Francis, pp. 121-137.

Nazeer, S., 2011. The competitive advantage of corporate philanthropy. University of Pretoria.

Nikolaeva, R., Bicho, M., 2011. The role of institutional and reputational factors in the voluntary adoption of corporate social responsibility reporting standards. Journal of the Academy of Marketing Science 39(1), 136-157.

Orlitzky, M., Schmidt, F.L., Rynes, S.L., 2003. Corporate social and financial performance: A meta-analysis. Organization Studies 24(3), 403-441.

Papava, V.G., 2010. The problem of Zombification of the Postcommunist Necroeconomy. Problems of Economic Transition 53(4), 35-51.

Papworth, T., 2013. The Trading Dead: The zombie firms plaguing Britain's economy, and what to do about them. Adam Smith Research Trust, England.

Perez-Batres, L.A., Doh, J.P., Miller, V.V., Pisani, M.J., 2012. Stakeholder pressures as determinants of CSR strategic choice: Why do firms choose symbolic versus substantive self-regulatory codes of conduct? Journal of Business Ethics 110(2), 157-172.

Pflugrath, G., Roebuck, P., Simnett, R., 2011. Impact of assurance and assurer's professional affiliation on financial analysts' assessment of credibility of corporate social responsibility information. Auditing: A Journal of Practice $\mathcal{E}$ Theory 30(3), 239-254.

Plümper, T., Troeger, V.E., 2007. Efficient Estimation of Time-Invariant and Rarely Changing Variables in Finite Sample Panel Analyses with Unit Fixed Effects. Political Analysis 15(2), 124-139.

Porter, M., Kramer, M., 2006. Corporate strategy and sociality: the relationship between corporate competence and corporate social responsibilty. Harvard Business Review 128(12), 76-99.

Ramus, C.A., Montiel, I., 2005. When are corporate environmental policies a form of greenwashing? Business \& Society 44(4), 377-414.

Ranängen, H., Lindman, Å., 2018. Exploring corporate social responsibility practice versus stakeholder interests in Nordic mining. Journal of Cleaner Production 197, 668-677.

Riyanto, Y.E., Toolsema, L.A., 2007. Corporate social responsibility in a corporate governance framework. Available at SSRN 987962.

She, C., Michelon, G., 2019. Managing stakeholder perceptions: Organized hypocrisy in CSR disclosures on Facebook. Critical Perspectives on Accounting 61, 54-76. 
Shen, G., Chen, B., 2017. Zombie firms and over-capacity in Chinese manufacturing. China Economic Review 44, 327-342.

Shleifer, A., Vishny, R.W., 2002. The grabbing hand: Government pathologies and their cures. Harvard University Press.

Sikka, P., 2010. Smoke and mirrors: Corporate social responsibility and tax avoidance, Accounting forum. Taylor \& Francis, pp. 153-168.

Simnett, R., Vanstraelen, A., Chua, W.F., 2009. Assurance on sustainability reports: An international comparison. The accounting Review 84(3), 937-967.

Siueia, T.T., Wang, J., Deladem, T.G., 2019. Corporate Social Responsibility and financial performance: A comparative study in the Sub-Saharan Africa banking sector. Journal of Cleaner Production 226, 658-668.

Storz, M., Koetter, M., Setzer, R., Westphal, A., 2017. Do we want these two to tango? On zombie firms and stressed banks in Europe.

Tan, Y., Huang, Y., Woo, W.T., 2016. Zombie firms and the crowding-out of private investment in China. Asian Economic Papers 15(3), 32-55.

Thorne, L., S. Mahoney, L., Manetti, G., 2014. Motivations for issuing standalone CSR reports: A survey of Canadian firms. Accounting, Auditing $\mathcal{E}$ Accountability Journal 27(4), 686-714.

Tran, N., O'Sullivan, D., 2018. The relationship between corporate social responsibility, financial misstatements and SEC enforcement actions. Accounting $\mathcal{E}$ Finance.

Urionabarrenetxea, S., Garcia-Merino, J.D., San-Jose, L., Retolaza, J.L., 2018. Living with zombie companies: do we know where the threat lies? European Management Journal 36(3), 408-420.

Velte, P., Stawinoga, M., 2017. Empirical research on corporate social responsibility assurance (CSRA): A literature review. Journal of Business Economics 87(8), 1017-1066.

Wagner, T., Lutz, R.J., Weitz, B.A., 2009. Corporate hypocrisy: Overcoming the threat of inconsistent corporate social responsibility perceptions. Journal of Marketing 73(6), 77-91.

Wang, Z., Reimsbach, D., Braam, G., 2018. Political embeddedness and the diffusion of corporate social responsibility practices in China: A trade-off between financial and CSR performance? Journal of Cleaner Production 198, 1185-1197.

Watson, L., 2015. Corporate social responsibility, tax avoidance, and earnings performance. The Journal of the American Taxation Association 37(2), 1-21.

Xie, X., Jia, Y., Meng, X., Li, C., 2017. Corporate social responsibility, customer satisfaction, and financial performance: The moderating effect of the institutional environment in two transition economies. Journal of Cleaner Production 150, 26-39.

Yu, W., Zheng, Y., 2018. The disclosure of corporate social responsibility reports and sales performance in China. Accounting $\mathcal{E}$ Finance.

Zhu, Y., Warner, M., Feng, T., 2011. Employment relations “with Chinese characteristics": The role of trade unions in China. International Labour Review 150(1 - 2), 127-143. 